\title{
EL PRIMER MODELO DE RECLUTAMIENTO FORZOSO EN ESPAÑA DURANTE LA EDAD MODERNA: LAS LEVAS PARA LOS PRESIDIOS (1634-1642)'
}

\section{THE FIRST MODEL OF FORCED RECRUITMENT IN SPAIN DURING THE EARLY MODERN PERIOD: THE LEVIES FOR THE PRESIDIOS (1634-1642)}

Antonio José Rodríguez Hernández

UNED

\section{RESUMEN}

A mediados del siglo XVII aparecen en España nuevos modelos alternativos de reclutamiento basados en la coerción. Los primeros fueron los diversos repartimientos de soldados realizados en Castilla tras la propuesta del conde-duque de Olivares de llenar los presidios, que contaron con aprobación de las Cortes. Estas levas establecían nuevas fórmulas de reclutamiento forzoso que servirán de base de otras posteriores. Este texto repasa la gestión del reclutamiento, utilizando fuentes originales. Para disponer de mayor perspectiva usaremos tanto la documentación producida directamente por la administración militar, como la de carácter local custodiada en archivos municipales.

Palabras clave: Reclutamiento, Presidios, conscripción, deserción y control social.

\begin{abstract}
In the middle of the 17th century, new alternative models of recruitment based on conscription arose in Spain. The first ones were the diverse quotas of soldiers realized in Castile after the proposal of the count-duke of Olivares to of fill the Presidios, which received the necessary approval of the courts of Castile. These levies established new prescription of forced recruitment that would be used as base to others enlistments. This paper addresses the management of that recruitment, using documentary sources. To have a wider perspective we will use both documents produced by the military administration and local material accumulated in municipal archives.
\end{abstract}

Keywords: Recruitment, Presidios, conscription, desertion, and social control.

1 Trabajo integrado en el proyecto de investigación Guerra, ejército y poder en la lucha por la conservación de la monarquía de Carlos II (HAR2016-80673-P). Abreviaturas: Archivo General de Simancas (AGS): Guerra Antigua (GA), Estado (E), Contaduría Mayor de Cuentas (CMC), Secretarías Provinciales (SP); Biblioteca Nacional (BN); Archivo Municipal de Burgos (AMBurgos); Archivo Municipal de Ponferrada (AMPonferrada); Archivo Municipal de Morón de la Frontera (AMMorón); Archivo Municipal de Marchena (AMMarchena); Legajo (Leg.), Libro de Actas (LA), manuscrito (ms.), folio (f.). 


\title{
RESUM
}

\section{El primer model de reclutament forçós a Espanya durant l'Edat Moderna: les lleves per als Presidis (1634-1642)}

\begin{abstract}
A mitjans del segle XVII apareixen a Espanya nous models alternatius de reclutament basats en la coerció. Els primers van ser els diversos repartiments de soldats realitzats a Castella després de la proposta del comte-duc d'Olivares d'omplir els presidis, que van comptar amb aprovació de les Corts. Aquestes lleves establien noves fórmules de reclutament forçós que serviran de base d'altres posteriors. Aquest text repassa la gestió del reclutament, utilitzant fonts originals. Per disposar de major perspectiva utilitzarem tant la documentació produïda directament per l'administració militar, com la de caràcter local custodiada en arxius municipals.
\end{abstract}

Paraules clau: Reclutament, Presidis, conscripció, deserció i control social. 
Las guerras de Italia enseñaron a los españoles a apostar por la calidad frente a la cantidad -manteniendo y disciplinando a sus soldados más allá del final de los conflictos bélicos-, creando un sistema militar en el que los profesionales eran la clave. ${ }^{2}$ La decisión española de mantener una infantería profesional con carácter autóctono, contrasta con la política de los monarcas franceses, que preferían mantener a sus súbditos -con la excepción de la nobleza-, alejados de la profesión militar, y apostaron por el mercenariado suizo, gascón o alemán. ${ }^{3}$ Realidad interpretada como la preferencia de España por un mercenariado autóctono, los soldados de los Tercios. Pero ver a éstos como unos mercenarios parece una interpretación algo simplista. Los soldados españoles de los Tercios eran voluntarios de cualquier origen social que pretendían ganarse la vida, adquirir honor y reputación, o ascender socialmente. ${ }^{4}$ Posibilidades que durante mucho tiempo el ejército ofreció, por lo que no faltaron los voluntarios, manteniendo éste una estructura profesional, en la que los ascensos y remuneraciones -regulados por las Ordenanzas Militares ${ }^{5}$ - eran acordes al valor y la experiencia. Soldados, que ante la clara voluntad de los reyes convirtieron el oficio de las armas en su forma de vida. Para ello, cuando se alistaban, firmaban un compromiso que los ataba al ejército hasta que murieran o fueran licenciados. ${ }^{6}$

2 RODRÍGUEZ HERNÁNDEZ, A.J. (2013): "Los hombres y la Guerra". En RIBOT, L.(Coord.): Historia Militar de España. Tomo III. Edad Moderna II. Escenario Europeo. Madrid, Ministerio de Defensa y Real Academia de la Historia, pp. 187-222.

3 POTTER, D. (2008): Renaissance France at War Armies, Culture and Society, 1480-1560. Woodbridge, Boydell, pp. 95-123.

4 THOMPSON, I.A.A. (2003): "El soldado del Imperio: Una aproximación al perfil del recluta español en el Siglo de Oro". Manuscrits, n²1, pp. 17-38.

5 Ordenanzas Militares de 1632, AGS, SP, Leg. 1.431.

6 RODRÍGUEZ HERNÁNDEZ, A.J. (2011): Los Tambores de Marte. El Reclutamiento en Castilla durante la segunda mitad del Siglo XVII (1648-1700). Valladolid, Universidad de Valladolid, pp. 87 y ss. 
La monarquía concentró sus recursos en la captación de profesionales que sólo debían rendir cuentas ante el rey y el Consejo de Guerra, siendo una de las pocas potencias que pudo construir un sólido y avanzado modelo de reclutamiento, centralizado y controlado directamente por la administración; ${ }^{7}$ en un tiempo en el que el método más usado era el indirecto, mediante la acción de los particulares: nobles, asentistas o mercenarios. Un modelo, conocido como sistema administrativo, ${ }^{8}$ que regulaba la elección de los oficiales que ejecutarían el reclutamiento -a los que se exigía varios años de servicio antes de acceder al cargo-, establecía de manera precisa los partidos de reclutamiento y el número de hombres, ${ }^{9}$ los pagos y tránsitos de las tropas. ${ }^{10}$ Todo ello pagado y organizado directamente por las autoridades militares ${ }^{11}$, siendo los capitanes los encargados directos de alistar sus compañías, sin que fuera necesario la intervención de las autoridades locales, y sin que éstas debieran obligar a nadie a alistarse. Su contribución era asegurar unos alojamientos adecuados y que los hombres pudieran encontrar los productos que necesitaban a unos precios apropiados de mercado, pudiendo ser lo primero bastante conflictivo. ${ }^{12}$ Así no se presionaba a los municipios, al recaer todas las responsabilidades en los capitanes y el Consejo de Guerra.

El principal problema del sistema era que todo dependía de la capacidad de encontrar voluntarios, algo cada vez más complicado, especialmente a partir de 1580, cuando los efectos de la crisis demográfica se hicieron patentes, haciendo que las compañías estuvieran lejos de completarse. ${ }^{13}$ Los

7 TALLETT, F. (1995): War and society in Early-Modern Europe, 1495-1715. Londres, Routledge, p. 73.

8 Sobre este sistema: THOMPSON, I.A.A. (1981): Guerra y decadencia. Gobierno y administración en la España de los Austrias, 1560-1620. Barcelona, Crítica, pp.129-180; PARKER, G. (1985): El Ejército de Flandes y el Camino Español 1567-1659. Madrid, Alianza, pp. 71-73; QUATREFAGES, R. (1983): Los Tercios. Madrid: Ed. Ejército, pp.423 y ss; MARTíNEZ RUIZ, E. (2008): Los Soldados del Rey. Los ejércitos de la Monarquía Hispánica (1480-1700). Madrid, Actas, pp.901-904.

9 Elección de capitanes, 27/4/1613. AGS, GA, Libro 96 f. 97.

10 Nombramiento como comisario e instrucciones a Francisco de Oviedo, Valladolid, 25/4/1604 AGS, GA, Libro 96 f.31.

11 Instrucción Real, Lisboa, 12/9/1619. AGS, GA, Leg. 839.

12 RODRÍGUEZ HERNÁNDEZ, A.J. (2014): "Milites Vs. Civitas: Análisis de los conflictos producidos por el reclutamiento de soldados voluntarios en las ciudades castellanas durante la segunda mitad del siglo XVII". Chronica Nova. Historia Moderna, n40, pp.77-105.

13 THOMPSON: Guerra y Decadencia..., p. 131 y ss. 
capitanes tenían instrucciones de reclutar hasta cierta cantidad de soldados -número fijado desde mediados del reinado de Felipe II en 250, cifra que se mantuvo hasta las primeras décadas del siglo XVII-, algo que no siempre se cumplía ante la falta de voluntarios, imponiéndose un límite hacia arriba pero no un número mínimo. La media real de soldados alistados en las compañías era mucho más baja: 123 hombres en 1594; cifra que bajó hasta los 105-107 en las primeras dos décadas del XVII. ${ }^{14}$ La brusca bajada en la eficacia del reclutamiento hará que desde 1624 el Consejo de Guerra reconozca que bastaban 100 hombres para formar una compañía ${ }^{15}$, si bien las ordenanzas militares de 1632 seguían indicando que las compañías en España debían tener 250 efectivos. ${ }^{16} \mathrm{El}$ reclutamiento administrativo necesitaba voluntarios -y su número siempre fluctuaba respecto a las condiciones de vida, las cosechas, la demografía, las plagas o las epidemias-, sin que se supiera a ciencia cierta cuántos hombres se podrían reunir cada año.

Estaba claro que era imposible que un país tan pequeño como España pudiera satisfacer la demanda de soldados impuesta por una monarquía global. Durante la década de 1630 esto se hizo más evidente, ante la crisis del modelo, que no llegaba a reunir los suficientes hombres. Los soldados españoles se habían convertido en un bien escaso que había que reservar para las operaciones más importantes y destacadas, y defender las zonas más sensibles, al ser las tropas de mayor confianza. ${ }^{17}$ No es de extrañar que durante las primeras operaciones militares de la Guerra de los Treinta años en el Sacro Imperio Germánico no hubiera ninguna unidad española integrada en el ejército de más de 9.000 hombres que formó España para apoyar al bando católico, y que se hizo con la victoria en Montaña Blanca (1620). La monarquía mandó soldados valones e italianos, y reclutó alemanes. Pero, aunque hubo oficiales españoles, ninguna unidad estaba compuesta por éstos. ${ }^{18}$ Hasta el envío a Alsacia del duque de Feria en 1633 no hubo tercios españoles combatiendo en Alemania. Algo que se produjo

14 THOMPSON: Guerra y Decadencia..., pp. 131-132; y RODRÍGUEZ HERNÁNDEZ: "Los hombres y la Guerra...", pp. 202-204.

15 Memoria de los distritos, Madrid, 5/7/1624. AGS, GA, Libro 96.

16 Ordenanzas Militares de 1632, AGS, SP, Leg. 1.431.

17 Consejo de Estado, 14/5/1634. AGS, E, Leg. 2.048 f. 45.

18 GUTHRIE, W.P. (2002): Battles of the Thirty Years War: From White Mountain to Nordlingen 1618-1635. Westport, Greenwood Publishing, pp. 61-62. PALAU CUÑAT, J. (1994): "La batalla de Weissenberg (Montaña Blanca), 1620". Dragona, n4, pp. 12-13. Cuentas de Hurtuño de Ugarte, 1617-22. AGS, CMC $3^{a}$ época, Leg. 706. 
debido a su vital objetivo: allanar el camino a la futura expedición militar del Cardenal Infante hacía Flandes. ${ }^{19}$

Ante la crisis del modelo tradicional voluntario se necesitaba otro alternativo, dándose los primeros pasos hacia la descentralización del sistema. Una política que destacará por ser errática, y que primero se centró en extender el reclutamiento indirecto, apelando a intermediarios -ya fueran asentistas $^{20}$ o nobles, siendo la respuesta de los últimos bastante tibia ${ }^{21}-$, que reunían hombres a cambio de dinero u otras contraprestaciones, entrando en juego la venalidad. ${ }^{22}$ Ellos se encargarían de sustituir momentáneamente a los capitanes profesionales que desde hacía más de 100 años se encargaban de reclutar voluntarios, teniendo como principal misión enviar tropas a los ejércitos europeos de la monarquía.

Rápidamente quedó patente que esto no era suficiente, por lo que al mismo tiempo se intentó recuperar las antiguas obligaciones militares de los municipios, y que éstos se encargaran de reunir los hombres suficientes

19 Consejo de Estado, 24/5 y 27/10/1633. AGS, E, Leg. 2.334.

20 Sobre los asientos: RIBOT, L. (2000): "Types of Armies: Early Modern Spain". En CONTAMINE, P.(Coord.), War and competition between States. Oxford, Oxford University Press, pp. 52-55. ANDÚJAR CASTILLO, F. (2006): "Empresarios de la guerra y asentistas de soldados en el siglo XVII". En GARCÍA HERNÁN, E. y MAFFI, D. (Eds.), Guerra y sociedad en la Monarquía Hispánica: Política, Estrategia y Cultura en la Europa Moderna (1500-1700). Madrid, Laberinto, Vol. II, pp. 375-394. RODRÍGUEZ HERNÁNDEZ, A.J. (2007): "Patentes por soldados. Reclutamiento y venalidad en el ejército durante la segunda mitad del siglo XVII". Chronica Nova, n³3, pp. 37-56.

21 Junta de Ejecución, 11/11/1634. Sumario de lo que han respondido algunos prelados y títulos, AGS, GA, Leg. 1.099. Coronelías de a pie y de a caballo de la Junta del Arzobispo de Granada, 2/6/1635, AGS, GA, Leg. 1.258. Conde de CLONARD (1862), Historia Orgánica de la Armas de Infantería y Caballería. Madrid, t. IV, pp. 409-410; MACKAY, R. (2007): Los Límites de la autoridad real. Resistencia y obediencia en la Castilla del siglo XVII. Valladolid, Junta de Castilla y León, pp. 120-134. THOMPSON, I.A.A. (1986): "El reinado de Felipe IV", en ANDRÉS GALLEGO, J. (coord.), Historia General de España y América. Madrid, Rialp, t. VIII, p. 459

22 JIMÉNEZ MORENO, A. (2009): “Honores a cambio de soldados, la concesión de hábitos de las Órdenes Militares en una coyuntura crítica: la Junta de Hábitos (1635-1642)". En SORIA MESA, E. y DELGADO BARRADO, J.M. (eds.), Las élites en la época moderna: la monarquía española, vol. 3, Economía y poder. Córdoba, Universidad de Córdoba, pp. 155-171. RODRÍGUEZ HERNÁNDEZ, A.J. (2012): "Servir al rey con hombres. Recompensas concedidas a élites y representantes del rey por su colaboración en el reclutamiento (1630-1700)". En ESTEBAN ESTRÍNGANA A. (ed.), Servir al rey en la Monarquía de los Austrias. Medios, fines y logros del servicio al soberano en los siglos XVI y XVII. Madrid, Sílex, pp. 415-443. 
para asegurar la defensa peninsular, aumentando la coerción. La fallida Unión de Armas había intentado sin éxito asegurar a la monarquía unos contingentes mínimos para afrontar sus empresas militares. Tras abandonar el proyecto, el conde-duque de Olivares intentará desarrollar un modelo alternativo que sólo afectará a Castilla, consiguiendo que las Cortes aprueben en 1634 la primera recluta forzosa que tendría como objetivo que los presidios mantuvieran sus dotaciones, para que así el reino estuviera bien defendido; ${ }^{23}$ cuestión sobre la que profundizaremos en este trabajo ante su importancia para los sistemas de reclutamiento venideros, ya que desde entonces los municipios cobrarán una importancia capital en el reclutamiento de sus naturales, la cual se mantendrá a lo largo de todo el siglo a pesar de los continuos cambios. ${ }^{24}$

\section{La primera leVA de los presidios (1634-35)}

\subsection{La propuesta al reino de 1634}

Aprovechando las quejas vertidas en el Consejo de Castilla en 1631 en base a las molestias y cargas que representaban para muchos pueblos los alojamientos y tránsitos de tropas que se reclutaban, el Valido hábilmente introdujo la idea de que si los presidios mantenían sus dotaciones -y una consignación económica periódica y suficiente-, dejaría de ser necesario que se realizaran levas, ya que los voluntarios fluirían directamente al ser las pagas puntuales. ${ }^{25}$ Durante la década de 1630 Olivares consiguió mejorar la financiación del dispositivo defensivo peninsular: los presidios. ${ }^{26}$ Un conjunto de guarniciones permanentes de infantería repartidas por las fronteras terrestres y marítimas. Éstas se encontraban en la frontera pirenaica -en los lugares y pasos más sensibles-, en las zonas costeras de mayor importancia, tanto en la península -incluida Portugal- como en las islas

23 THOMPSON, I.A.A. (1990): "Aspectos de la organización naval y militar durante el ministerio de Olivares". En ELLIOTT, J.H. y GARCÍA SANZ, A. (coords.), La España del Conde Duque de Olivares. Valladolid, pp. 251-258; MACKAY, Los límites..., pp. 57-70. RODRÍGUEZ HERNÁNDEZ, A.J. (2012): "Las Cortes de Castilla y la leva para los Presidios: La gestión de la primera recluta obligatoria de los Austrias". En PÉREZ ÁlVAREZ, M.J., RUBIO PÉREZ, L.M. y MARTíN GARCÍA, A. (eds.), Campo y campesinos en la España Moderna. Culturas políticas en el mundo hispano. León, Fundación Española de Historia Moderna, pp. 1731-1744.

24 RODRÍGUEZ HERNÁNDEZ: Los Tambores de Marte..., pp. 145-196.

25 ELLIOTT, J.H. y DE LA PEÑA, J.F. (1981): Memoriales y cartas del Conde Duque de Olivares. Tomo II. Política interior: 1628 a 1645. Madrid, Alfaguara, pp. 104-105.

26 Decreto de su majestad, Madrid, 22/6/1631. AGS, GA, Leg. 1.037. 
atlánticas y mediterráneas, y el Norte de África. Unas guarniciones que tenían una dotación teórica de 18.000 plazas. ${ }^{27}$

La medida tardó en cuajar ante los problemas de financiación que supondría su implantación, y la apurada situación financiera, como advirtieron las Cortes de 1632. ${ }^{28}$ Sin embargo, al tener claro que estallaría una nueva guerra con Francia, se debía mejorar la defensa fronteriza que los presidios representaban, al ser el único cuerpo de infantería profesional que había en España más allá del tercio de la Armada destacado en Andalucía. ${ }^{29}$ A comienzos de 1634 Olivares propuso la forma de "llenar los Presidios", debatiéndose posteriormente el tema en las Cortes ${ }^{30}$ y en los Consejos de Estado y Guerra. ${ }^{31}$ La propuesta pretendía atender tanto al mantenimiento -asegurando un asiento anual por valor de 270 millones de maravedíes con Octavio Centurión- como la completa dotación de los presidios. Para que estas guarniciones fueran más atractivas se proponían medidas para mejorar la vida de los soldados, asegurar su paga puntual, posibilidades de ascenso, premios y movilidad, especialmente para los que defendían los presidios norteafricanos. La medida de llenar los Presidios se vendía como un gran beneficio para Castilla, que estaría mejor defendida y se vería libre de otras levas. Para ello, el reino -por provincias, y según sus vecindarios-, debía poner en los Presidios la gente que faltaba para cubrir su dotación, quedando su mantenimiento económico en manos de los Millones y otros ingresos. Las provincias tendrían libertad para realizar la recluta, no sobrecargándose los lugares pequeños y de poca vecindad. Para animar la colaboración de las ciudades, se las prometía que podrían echar mano de los muchos desocupados y vagabundos que había, a los que se persuadiría para alistarse. En ningún caso el reclutamiento se efec-

27 Relación de la gente que conforme al nuevo pie que ha de haber en los Presidios, 5/2/1634 Relación de la gente que ha de haber en los presidios conforme al nuevo pie de que queda bajado, Madrid, 7/2/1634. AGS, GA, Legs. 1.095 y 1.038. Para una visión general: CONTRERAS GAY, J. (1998): "Consideraciones generales sobre la defensa de la Península entre 1580 y 1640". En Mediterráneo: hechos de relevancia histórico-militar y sus repercusiones en España: V Jornadas Nacionales de Historia Militar. Sevilla: Universidad de Sevilla, pp. 647. 664.

28 Consejo de Guerra, 25 de agosto 1632. Cédula Real, 27/7/1632. AGS, GA, Leg. 1.098. También: Actas de las Cortes de Castilla, Vol. LI, p. 33 y ss.

29 Consejo de Guerra, 27/1/1634. AGS, GA, Leg. 1.098.

30 MACKAY, Los límites..., pp. 57-70. Acuerdo que el reino hizo en 25/2/1634. AGS, GA, Leg. 1.095.

31 Consejo pleno de Estado y Guerra, 3/3/1634. AGS, GA, Leg. 1.095. 
tuaría mediante la fórmula habitual, y no se permitiría que las tropas marcharan con banderas y cajas. Así las ciudades no se verían sobresaltadas, y se evitarían daños y problemas. Incluso se establecían castigos para los futuros desertores, que debían ser capturados si volvían a sus hogares, y evitar así nuevas levas para cubrir las bajas. ${ }^{32}$

El acuerdo, aceptado por el reino en las Cortes de febrero de 1634, ponía las bases del servicio. ${ }^{33}$ El reino se encargaría de que los presidios mantuvieran su dotación de unos 18.000 hombres, repartiéndose los 12.000 hombres que faltaban entre todas las provincias por cupos. Los gastos de reclutamiento y mantenimiento de las tropas correrían a cargo del rey, por lo que a cada provincia se enviaría el dinero necesario. Según el acuerdo, el reino debía suplir las bajas cuando se debieran a la muerte o fuga de los soldados. Sólo se excusaba el reemplazo en caso de que el rey enviara a éstos a combatir a otras partes. Con este servicio el reino conseguía evitar las vejaciones que provocaban las levas, anulándose todas las que estaban teniendo lugar. El servicio duraría seis años. El último punto de las condiciones ofrecidas era para los consejeros el más polémico, ya que determinaba que si no era posible encontrar voluntarios los pueblos podrían acudir al sorteo o quintar, lo cual suponía una fórmula obligatoria de reclutamiento, que quedaba justificada debido a que las tropas no servirían fuera de España, y que el reclutamiento era para defender el reino. ${ }^{34}$

La recluta se efectuó según unos cupos basados en la población teórica de cada una de las 17 provincias en las que se dividió Castilla, las cuales supuestamente tenían 1.015 .000 vecinos; ${ }^{35}$ cifra ponderada y redondeada que era algo inferior a otros recuentos demográficos del periodo. ${ }^{36}$ En total se sacarían 12.000 soldados, quedando al margen las Provincias Vascas, Canarias y los lugares que estuvieran a menos de ocho leguas de un Presidio; si bien esto último no se cumplió. Los vecindarios se corrigieron continuamente ante su falta de fiabilidad, aunque de media se debía sacar un

32 Proposición para llenar los Presidios y conservarlos, s/f. AGS, GA, Leg. 1.095.

33 Acuerdo que el reino hizo en 25/2/1634. Papel del reino sobre llenar los Presidios, 2/3/1634. AGS, GA, Leg. 1.095.

34 Consejo pleno de Estado y Guerra, 3/3/1634. Acuerdo que el reino hizo en 25/2/1634. Forma que las provincias han de guardar en juntar la infantería, conducirla, y los privilegios concedidos, s/f. AGS, GA, Leg. 1.095.

35 Relación de la vecindad que hay en las provincias del reino, s/f. AGS, GA, Leg. 1.095.

36 ELLIOTT, J.H. (2004): El conde-duque de Olivares. Barcelona: Crítica, p.562. DOMINGUEZ ORTIZ, A. (1963): La Sociedad Española en el Siglo XVII. Madrid, CSIC, t. 1, pp. $110-112$. 
soldado por cada 85 vecinos. ${ }^{37}$ Los cupos fueron más o menos respetados y aceptados, debatiéndose en las diferentes ciudades con voto en cortes la cuestión durante los meses siguientes. ${ }^{38}$

\subsection{Los resultados}

Los cupos no se cubrieron de manera significativa hasta mediados de 1635. Numerosos informes revelan las continuas llegadas, si bien las cuentas no están completas, y no siempre los secretarios pudieron incluir a todos los hombres enviados ante la magnitud de la operación, ya que además debían intentar cruzar la información entre las cartas y testimonios que enviaban los corregidores y los informes administrativos llegados desde los presidios, más precisos y concluyentes. En marzo se contabilizaba la llegada de 6.018 hombres. ${ }^{39}$ A comienzos de abril eran 7.523, aunque ya habían huido 1.543. ${ }^{40}$ Según los informes finales faltaron por entregar 2.064 soldados, bien porque las autoridades no los alistaron, bien porque huyeron por el camino o se despidieron a su llegada al ser inútiles para el servicio. ${ }^{41}$

A lo largo del mes de abril -un año después de su comienzo- se realizó un informe muy preciso de cómo estaban cumpliendo los diversos partidos. Los principales problemas estaban en las circunscripciones más grandes. Sevilla no había entregado muchos hombres debido a la poca implicación de algunos corregidores. De hecho, las órdenes no llegaron hasta el verano a algunos territorios de la nobleza, como la villa de Morón de la Frontera. ${ }^{42}$ Madrid también había sido problemática, pero pactó el cumplimiento del cupo en base a poder reclutar voluntarios, acordándose con los gremios la entrega 200 hombres. Pero a esas alturas el principal escollo era el alto grado de fugas, tanto antes como después de llegar a su destino. Aunque Murcia había reunido los hombres pedidos y los había enviado a

37 Relación de los 12.000 hombres que ha de dar el reino, s/f. AGS, GA, Leg. 1.038. Relación de la gente que está repartida a todas las ciudades y cabezas de partidos, $s / f$. Repartimiento de los infantes que se han de levantar para los Presidios, s/f. AGS, GA, Leg. 1.095.

38 Acuerdos del cabildo de Burgos, marzo y abril 1634. AMBurgos, LA de 1634 f.24 y ss.

39 Junta o comisión del conde de Castrillo, Madrid, 18/3/1635. AGS, GA, Leg. 1.121.

40 Notas sobre los informes realizados en marzo y abril de 1635. AGS, GA, Leg. 1.132.

41 Notas sobre lo que falta por entregar del primer repartimiento, 4/12/1636. AGS, GA, Leg. 1.194. Carta de Matías Fernández Zorrilla, Madrid, 21/4/1635. AGS, GA, Leg. 1.121.

42 Cédula de García Sarmiento de Sotomayor, Asistente de Sevilla, Sevilla, 18/7/1635. AMMorón, Leg. 649. 
la frontera valenciana, una noche -estando en el castillo de Játiva-, buena parte de ellos se fugaron ante la falta de dinero para su socorro. ${ }^{43}$

Empero, el grado de cumplimiento y aceptación fue alto, y durante la primavera de 1635 muchos de los corregidores remisos comenzaron a despachar las tropas que faltaban. El territorio menos dispuesto a cumplir era Granada, que se quejaba de que debía acudir a sus costas para defenderlas, y contribuir económicamente socorriendo a las guarniciones profesionales presentes, por lo que en junio de 1635 sólo había entregado en Málaga 275 hombres, lejos de los 1.320 asignados. La cuestión que más empañaba el servicio estaba siendo las fugas, que en Cádiz habían sido exorbitadas. Desde algunos sectores se achacaba el problema a la falta de camas, pero la principal dificultad estaba en la falta de un socorro adecuado para los bisoños y la carestía creada artificialmente ante la llegada de muchos hombres en poco tiempo. ${ }^{44}$ Durante el verano siguieron llegando tropas a cuenta de los que todavía no se habían remitido. Incluso algunos partidos empezaron de forma esporádica a cubrir las bajas de los hombres entregados meses atrás. Las provincias de Córdoba y Jaén dieron otros 387 hombres para cubrir parte de los 1.400 que hasta el momento habían huido. ${ }^{45}$ Los envíos a Cataluña fueron algo más tardíos, aumentando poco a poco el número. ${ }^{46}$ En noviembre se habían entregado 1.253, y a Toledo y Cuenca sólo les faltaban por entregar 16 y 20 hombres respectivamente; aunque Murcia debía reponer los 187 que se habían fugado de camino. ${ }^{47}$ En muy poco tiempo los corregidores escribieron indicando que los soldados empezaban a volver sin licencia, por lo que se debieron tomar medidas. Se persiguió a los fugados, y se remitieron listados a los lugares por los que servían para que fueran apresados si volvían. ${ }^{48}$ También se ordenó

43 Relación de los 12.000 hombres que se ha de conducir, Madrid, 19/4/1635. AGS, GA, Leg. 1.121 .

44 Relación de lo que ha obrado el cuerpo de la junta que está a cargo del conde de Castrillo, Madrid, 29/6/1635. AGS, GA, Leg. 1.144.

45 Relación de la gente que ha llegado, Cádiz, 31/7/1635. Carta de Juan de Castro y Castilla, Cádiz, 5/8/1635. AGS, GA, Leg. 1.147.

46 Relación de la gente que a la fecha se ha entregado, Barcelona, 13/4/1635. AGS, GA, Leg. 1.146.

47 Relación de los soldados que están en las atarazanas de Barcelona, 11/8/1635. Informes de los soldados repartidos; los entregados en Barcelona; y los que faltan de Conducir, 7/11/1635. AGS, GA, Leg. 1.132.

48 Carta del gobernador de Llerena, 22/9/1635. Carta de la princesa Margarita, Gobernadora de Portugal, Lisboa, 19/2/1635. AGS, GA, Legs. 1.140 y 1.145. 
a los corregidores que capturaran en sus distritos a todos los soldados que hubiera sin licencia -aunque no vinieran de los presidios-, medida que por primera vez se tomaba en España, la cual pretendía dificultar que pudieran volver a sus hogares. ${ }^{49}$

La calidad de los reclutados era mala y muchos ministros reconocían que la mayoría eran jornaleros apresados, que incluso estaban casados y tenían hijos. ${ }^{50}$ Algunos oficiales no aceptaron a parte de las tropas, y desde Cádiz se avisó que no se habían recibido 50 por considerarlos mendigantes que venían sin espadas y que no parecían de provecho para la infantería. ${ }^{51}$ La leva no fue fácil, y algunos municipios prendían hasta 40 hombres para cumplir con un único soldado. Tampoco los comisarios que conducían las tropas salían indemnes de las críticas, ya que se decía que en el tránsito muchos liberaban a los soldados a cambio de dinero, poniendo a otros en su lugar, estando al orden del día los fraudes. A pesar de que las tropas solían hacer su viaje acompañados por guardas, y con esposas y grilletes -siendo incluso maltratados, como si fueran prisioneros-, hubo casos en los que sujetos armados se concentraron para liberar a los reclutas. Además, los municipios entregaban hombres que no siempre cumplían las condiciones mínimas de un recluta medio, de ahí que algunos oficiales expresaran que en estas levas sólo venían "viejos, ciegos, mancos y tullidos". ${ }^{2} \mathrm{La}$ llegada de esa gran cantidad de gente inútil acrecentaba los gastos y la necesidad de los hospitales militares. Cuestión que se agravaba debido a que los pueblos enviaban a los soldados descalzos y sin vestuario adecuado para aguantar el invierno, teniendo los reclutas un aspecto lamentable. Pocos perseverarían en el oficio militar, y los que podían, y reunían el dinero necesario, intentaban comprar su libertad a sus capitanes. No es de extrañar que el Consejo de Guerra criticara abiertamente la leva ante el gasto realizado, al ser un esfuerzo inútil. Incluso se afirmó que el reclutamiento había generado más daños que soluciones, pues las levas involuntarias no funcionaban y no servían para el objetivo marcado de llenar los presidios. Lo que se necesitaba realmente era voluntarios; cuestión que quedaría en saco roto ante la renovación del servicio. ${ }^{53}$

49 Cartas de los corregidores de Anquera, Madrigal, Murcia y Guadix, 11, 14, 17 y 30/4/1635. AGS, GA, Leg. 1.146.

50 Carta de Juan de Castro y Castilla, Cádiz, 5/8/1635. AGS, GA, Leg. 1.147.

51 Carta de Juan de Velasco, Cádiz, 18/3/1635. AGS, GA, Leg. 1.145.

52 Carta de Juan de Velasco, Cádiz, 18/6/1634. AGS, GA, Leg. 1.124.

53 Consejo de Guerra, 18 y $31 / 5,5$ y 14/7, 8 y 18/8 y 27/10/1635. AGS, GA, Leg. 1.124. 
Tabla 1: Resultados de la leva de los Presidios por partidos (abril 1635)

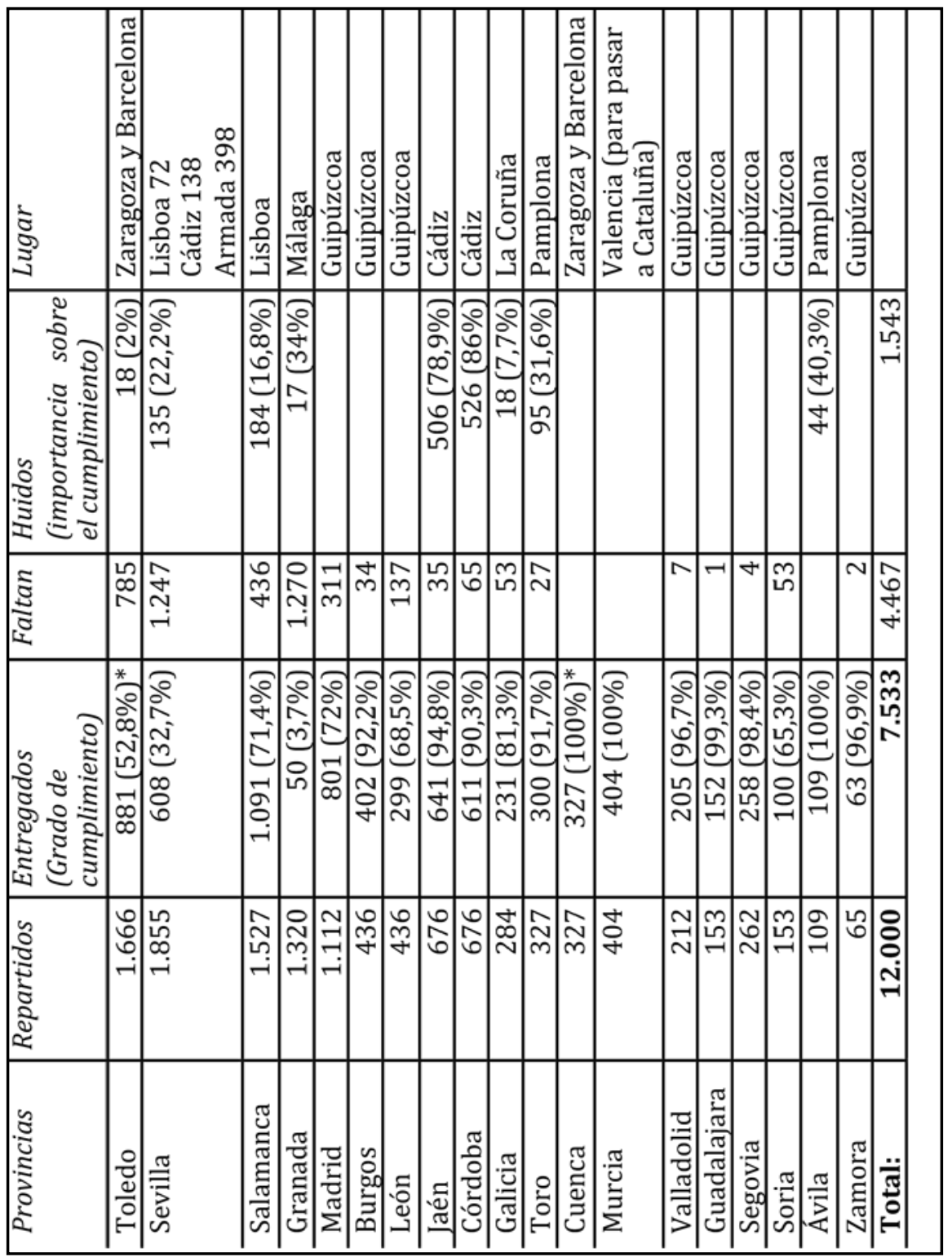

Fuente: AGS, GA, Legs. $1.121,1.132$ y 1.145. (*)=En noviembre se informaba que Toledo había entregado 1.001 hombres en Cataluña y otros 649 en Aragón, por lo que sólo quedaban por entregar 16. Cuenca había remitido 197 a Cataluña y 110 a Aragón, faltando 20. 


\subsection{La llegada a los presidios}

El aumento del número de bisoños en los presidios acrecentó los problemas estructurales de éstos, ya que no se había previsto su llegada y no se había aumentado su dotación económica. Los soldados sobrevivían en unas condiciones lamentables, con incomodidades y hacinados. ${ }^{54}$ Faltaban alojamientos adecuados ante el incremento de las dotaciones -incluso algunos soldados debieron dormir al raso ante la escasez de lugares apropiados-, y la carencia de camas y ropa de abrigo fue difícil de solucionar conforme llegaba el invierno. Muchos presidios como Cádiz o Pamplona compraron camas -365 y 289 respectivamente-, pero los fondos para costearlas fueron insuficientes, y aunque los soldados dormían de dos en dos, se calculaba que cada una costaba 166 reales y medio. ${ }^{55}$ Los nuevos soldados procedían de las capas sociales más pobres, por lo que no tenían medios para proporcionarse un vestuario adecuado y pasaban frío. Cuestión que se agravaría cuando en algunos presidios, como en Cádiz, la falta de consignaciones económicas periódicas y el incremento del coste de pan hizo que parte de las tropas no pudieran procurarse diariamente este alimento básico. Por ello las autoridades militares insistieron en dar a cada soldado al menos un socorro diario de 1 real de vellón y pan de munición. La precaria situación de los nuevos soldados impulsó a muchos a fugarse, a pesar de que si eran capturados se les condenaba a recibir azotes y a pasar entre 4 y 6 años en las galeras; penas que recibieron los 15 fugitivos apresados entre agosto y diciembre de 1635. Pero no parece que esa medida draconiana evitase de manera significativa las fugas ante la desesperación de muchos soldados, que no sólo eran forzados a alistarse, sino que además no recibían lo necesario para subsistir. ${ }^{56}$

A pesar de los esfuerzos, el mayor problema siguió siendo la poca continuidad de los soldados, ya que muchos desertaron cuando se presentó la

54 Consejo de Guerra, 14/6/1634. AGS, GA, Leg. 1.096.

55 Consejo de Guerra, 15 y 26/6, y 1/8/1635. AGS, GA, Leg. 1.120. Relación del estado del alojamiento, Pamplona, 28/6/1635. Relación de lo que costará cada cama, s/f. AGS, GA, Leg. 1.133. Cartas de Leonardo de Sorca Camargo y Francisco Lario de Losada, Cádiz, 3/6 y $30 / 11 / 1635$. AGS, GA, Leg. 1.148.

56 Consejo de Guerra, 28/8, 2/9 y 28/11/1635. Junta que se hace en la posada del conde de Castrillo, 21/8/1635. AGS, GA, Leg. 1.121. Orden al marqués de Monesterio, asentista de los presidios, Madrid, 23/10/1635. AGS, GA, Leg. 1.123. Carta de Juan de Velasco, Cádiz, 5/12/1635. AGS, GA, Leg. 1.140. 
oportunidad. ${ }^{57}$ En Cádiz entraron hasta mediados del mes de junio 1.168 soldados de los partidos de Jaén, Córdoba y Sevilla. En menos de tres meses sólo quedaban 279 , uno de cada cuatro. ${ }^{58}$ De poco servía el esfuerzo si no se mejoraba la situación en los Presidios, que no podían estar herméticamente cerrados, por lo que consecuentemente los forzados intentaban volver a sus casas. Según otro informe, hasta el verano de 1635 habían llegado a Cádiz 2.033 hombres de Jaén, Córdoba y Sevilla, de los que 156 no fueron admitidos en un primer momento por ser inútiles para el servicio, recibiéndose al sueldo 1.877. De ellos, a finales de julio -tres meses después de que llegara la primera tropa- 1.563 habían huido, 14 habían muerto o habían sido despedidos y 300 seguían en servicio en el presidio. Sólo un $15 \%$ había perseverado en el oficio militar. ${ }^{59}$

A pesar de lo ocurrido en Cádiz, debido a la improvisación, el balance en otros presidios fue más positivo. En Fuenterrabía y San Sebastián la llegada fue significativa. En febrero de 1634 había sólo 548 soldados, a principios de agosto dicha cifra se había triplicado y llegaba a los 1.620 hombres. ${ }^{60}$ También en Aragón los nuevos reclutas contribuyeron notablemente a aumentar su dotación. Entre finales de junio de 1634 y finales de agosto del año siguiente habían llegado 722, muriendo y fugándose 190 (el 26\%). Un balance basta positivo. Incluso los oficiales del sueldo justificaban el nivel de fugas debido a que no había hospital, faltaban medicinas, médicos y camas. Buena parte de los hombres debían dormir en el suelo, ya que, aunque se proveyó dinero para 265 camas, el precio era más elevado y no se habían podido enviar. ${ }^{61}$ De hecho -a pesar de las fugas y de que 300 de ellos fueran enviados a la frontera navarra para participar en la invasión que se realizaba en Francia-, a mediados de 1637 quedaban aún 53 soldados de estas tropas, cerca del $25 \%$ del total de los hombres presentes. ${ }^{62}$

57 Memoria de los oficiales reales de Cádiz, 17/12/1634. AGS, GA, Leg. 1.115.

58 Relación de la infantería bisoña, Cádiz, 15/7/1634. AGS, GA, Leg. 1.095.

59 Relación de la gente que ha llegado, Cádiz, 31/7/1635. AGS, GA, Leg. 1.147.

60 Relación del número de gente, Madrid, 9/12/1634. AGS, GA, Leg. 1.096.

61 Carta de los oficiales al sueldo de Zaragoza, 28/8/1635. Relación particular de la gente que ha venido de Castilla, Zaragoza, 28/8/1635. AGS, GA, Leg. 1.147.

62 Relación de los soldados efectivos, Zaragoza, 31/3/1637. Muestra de los presidios, 31/3/1637. Carta de Juan Sáez de Arriaga, Zaragoza, 31/3/1637. AGS, GA, Leg. 1.195. 
Tabla 2: Hombres entregados en los presidios durante 1635:

\begin{tabular}{|c|c|c|c|c|}
\hline Presidio de Entrega & $\begin{array}{ll}\begin{array}{l}\text { Fecha del } \\
\text { informe }\end{array} & \\
\end{array}$ & Entregados & $\begin{array}{l}\text { Fugados, } \\
\text { despedidos }\end{array}$ & $\begin{array}{ll}\text { muertos } & o \\
\end{array}$ \\
\hline Cádiz & mayo & 1.388 & & $1.221(87,9 \%)$ \\
\hline Cataluña & febrero & $\begin{array}{r}635 \\
\text { noviembre; } 1.253 \\
\end{array}$ & & $92(14,4 \%)$ \\
\hline Aragón & agosto & $\begin{array}{r}722 \\
\text { noviembre; } 759\end{array}$ & & $190(26,3 \%)$ \\
\hline Navarra & marzo & 407 & & $147(36,1 \%)$ \\
\hline Guipúzcoa & marzo & 1.733 & & $521(30 \%)$ \\
\hline Galicia & marzo & 236 & & $34(14,4 \%)$ \\
\hline Portugal & febrero & 1.163 & & $184(15,8 \%)$ \\
\hline Peñón Vélez de la Gomera & abril & 21 & & \\
\hline Armada & febrero & 398 & & \\
\hline Total: & & 6.703 & & $2.389(35,6 \%)$ \\
\hline
\end{tabular}

Fuente: AGS, GA, Legs. 1.121, 1.132, 1.144 y 1.147.

\section{La CONTINUIDAD DEL SERVICIO Y SU GESTIÓN 1635-1642}

El servicio de los presidios continuó durante ocho años, ajustándose distintos repartimientos. Unos estaban justificados por los incumplimientos del reino y las excesivas fugas de soldados; mientras que otros se realizaron para atender al mantenimiento de las dotaciones teóricas de los presidios. La gestión de la mayoría de ellos fue muy parecida. En total se realizaron al menos seis repartimientos que pretendían reunir 42.727 hombres, estando la cifra muy cerca de los 44.000 que Olivares demandó a Castilla y las Indias dentro de su Unión de Armas. ${ }^{63}$

Cualquier reparto era complicado, no sólo por lo difícil que era alcanzar el cupo asignado, sino también por el hecho de que las propias comunidades debían gestionar el reclutamiento y transporte de las tropas. Hasta el reparto de 1639, los costes fueron asumidos por las arcas locales. Desde los comienzos del servicio se insistió en que los hombres se llevaran "con prisiones y guardias", lo que aumentaba los costes. Cada comisario, alguacil armado o guardia debía ser pagado durante los días que le llevara su ocupación. Esto generaba unos costes excesivos, ya que había pueblos que debían enviar uno o dos soldados a cientos de kilómetros de distancia, 
y los comisarios debían ser pagados tanto durante el viaje de ida como el de vuelta, al no concentrarse las tropas en las capitales de partido; 64 algo que tras la experiencia se remediaría años después para ahorrar costes.

Otro problema era que todas estas demandas de soldados, y el dinero necesario para conducirlos, llegaban en un momento en el que comenzaban a proliferar otras demandas de carácter militar. Una escalada de peticiones que empezaban a colapsar las arcas de muchos municipios. En 1639 Marchena tuvo que entregar 25 soldados para los presidios, y pagar 200 reales de vellón por cada soldado; todo a cargo de los bienes de propios del concejo, pese a su lamentable estado. La ciudad cumplió, pero la petición llegaba en un momento de enormes obligaciones, ante las demoras del pago de los Millones, y la petición extraordinaria de enviar grano para el ejército. La cuestión económica sólo se pudo solucionar al permitirse imponer nuevos arbitrios sobre el consumo: 2 maravedíes por cada libra de aceite, otros 2 por cada libra de carne y tocino que se consumiera en la villa, y un real por cada cabeza de ganado vendida. Nuevos impuestos que encarecerían el nivel de vida de la población. ${ }^{65}$

En ocasiones se generaron diversos problemas a la hora de repartir los cupos entre las cabezas de provincia y sus jurisdicciones. ${ }^{66}$ Se solían usar parámetros poco claros para dividir el esfuerzo humano, los cuales se decidían en las cabezas de las provincias y no por el Consejo de Guerra. En muchos casos las proporciones no eran nada equitativas, y se sobrecargaba a algunos lugares frente a otros, siendo los aportes de las grandes ciudades con voto en cortes algo moderadas en relación al resto. Los problemas y quejas sobre los cupos repartidos internamente incidían en el grado de cumplimiento. En el repartimiento ajustado en 1640, el Reino de Sevilla debía aportar 1.266 hombres, pero sólo había podido remitir 993 ante la negativa de muchas jurisdicciones a cubrir el cupo, además de que los señores -especialmente cuyos estados estaban colindantes con la frontera portuguesa- se negaban a contribuir, aludiendo a sus privilegios y a la

64 Cédula Real refrendada por el Asistente de Sevilla, Sevilla, 12/1/1636. AMMarchena, Libro Registro de Órdenes 69. Acuerdos del 2/1 y 21/7/1636. AMPonferrada, Leg. 5, LA n 3 fs. 366 y 387.

65 Acuerdos del 25/1, 18/2, 17/3 y 17/4/ 1639. Copia de las órdenes, Sevilla, 24/1/1639. AMMarchena, LA n 7 fs. 3, 5, 10, 17 y 32. Relación de la gente que se ha recibido, Cádiz, 19/5/1639. AGS, GA, Leg. 1.261.

66 ARTAZA, M.M. (1998): Rey, Reino y Representación. La Junta General del Reino de Galicia (1599-1834). Madrid, CSIC, pp. 270-272. 
defensa del territorio. ${ }^{67}$ Estas cuestiones también resucitaban viejas desavenencias locales. En 1634 a la villa de Ponferrada la tocó contribuir inicialmente con 16 soldados de los 437 que debía aportar León; pero un mes después se le incrementó el número en otros 3 , tras rehacerse los cómputos debido a que se debió rebajar el número a algunas localidades pequeñas. La villa cumplió, pero en marzo del año siguiente desde León llegaron distintas instancias para que entregara dos hombres que supuestamente faltaban. Los informes eran erróneos y Ponferrada sólo debía entregar un soldado más en sustitución de uno que había muerto por el camino. La villa cumplió, a pesar de que las indagaciones molestaron profundamente al cabildo y reavivaron sus desavenencias con la capital leonesa. ${ }^{68}$

Dentro del sistema, uno de los grandes cambios fue la leva ajustada en 1639, que se conocería como la leva del uno por ciento, la cual -al contrario de lo ocurrido anteriormente- estuvo gestionada por la Junta de Coronelías. ${ }^{69}$ En esta ocasión los cupos fueron más imprecisos, a pesar de que las órdenes indicaban claramente que se debía alistar a uno de cada 100 vecinos, pudiéndose excusar las localidades que no llegaban a los 50 , excluyéndose del cómputo de la vecindad las viudas, los clérigos y los soldados de milicias. ${ }^{70}$ La formulación de la leva era mucho más novedosa y atípica que las anteriores, ante la generalización de la misma y la aparición de algunas excepciones, modelándose las aportaciones a lo largo de varios meses. Como novedad algunos partidos de Castilla la Vieja -como Burgos, Palencia o Valladolid- fueron exceptuados debido a su implicación en el reclutamiento de milicias, y el alojamiento de tropas que habían defendido la frontera de Fuenterrabía. Pero la gestión se extendió espacialmente y se dejaba en manos de los corregidores, que debían hacer frente a cupos menores que en las levas pasadas, aunque eran más los agentes implicados. Se intentó de manera particular que los territorios de las órdenes militares contribuyeran separadamente para que cubrieran en-

67 Cédula de García Sarmiento, Asistente de Sevilla, Sevilla, 10/4/1641. AMMarchena, Libro de Registro de Órdenes 69. Cuentas de Fernando de Madrid sobre los gastos de levantar y conducir 1.266 infantes al presidio de Cádiz, 1639. AGS, CMC $3^{a}$ época, Leg. 1.935 f. 6. Relación de los 8.042 soldados con que sirve el Reino, 11/9/1641. AGS, GA, Leg. 1.387.

68 Acuerdos del $28 / 4,5$ y $27 / 5$ y $24 / 7 / 1634$. Acuerdos del 26/3 y 30/5/1635. AMPonferrada, Legajo 5, LA n 3 fs. 276,279, 282, 292, 325 y 339.

69 Junta de Coroneles, 17/1/1639. AGS, GA, Leg. 1.261.

70 Junta de Coroneles, 10/7/1639. Cédula Real, 1/7/1639. AGS, GA, Leg. 1.258. Listado de los corregidores que participan, s/f. AGS, GA, Leg. 1.277. 
teramente los cupos, generándose quejas y el solapamiento de partidos. ${ }^{71}$ Otra novedad importante fue que con cierto éxito $-y$ fuera de los cupos establecidos en Castilla- se extendió el reclutamiento por la Corona de Aragón. Entre Valencia, Aragón ${ }^{72}$ y Mallorca se reunieron 1.140 soldados, si bien no se tuvieron en cuenta los vecindarios, sino que se establecieron cupos, y al contrario de lo que sucedía en Castilla las tropas se estructuraban en compañías, dirigidas por sus propios capitanes. ${ }^{73}$

El servicio en Castilla se efectuó de manera diferente, y algunos corregidores realizaron nuevos padrones para contabilizar su población. ${ }^{74}$ Pero no se configuró un vecindario general, sino que la mayoría de los corregidores realizaron estimaciones poblacionales y establecieron un cupo. ${ }^{75}$ Algo especialmente evidente para el caso de grandes ciudades como Sevilla o Madrid, en las que nunca se tuvo en cuenta los vecinos reales. Madrid debía contribuir con 400 hombres, a lo que puso enormes pegas. La ciudad intentó contribuir con dinero y se quejó del importante número de milicianos, de genoveses y otros extranjeros que vivían en la capital, y que por lo tanto estaban exentos. De hecho, a duras penas remitió 358 hombres. ${ }^{76}$ Los cupos se cumplieron, e incluso se sobrepasaron, ${ }^{77}$ aunque no siempre los señores remitieron los soldados asignados. ${ }^{78}$ Los corregidores lograron sus objetivos gracias a que utilizaron su poder, ya que se les autorizó el uso

71 Junta de Coroneles, 17/1, 11 y 22/3 y 18/4/1639. AGS, GA, Leg. 1.261.

72 Sobre el reclutamiento en estos territorios: VILA LÓPEZ, C.M. (1979-80): "La aportación valenciana a la guerra con Francia (1635-1640)", Estudis, n 8, pp. 125-142. SOLANO CAMÓN, E. y SANZ CAMAÑES, P. (1998): "La contribución de Aragón en las empresas militares al servicio de los Austrias", Studia Historica. Historia moderna, n 18, pp. 237-264.

73 Junta de Coroneles, 17/1, 11 y 22/3/1639. AGS, GA, Leg. 1.261. Carta del Virrey de Mallorca, 19/6/1639. Carta del Gobernador de Aragón, Zaragoza, 24/5/1639. AGS, GA, Leg. 1.262 .

74 Testimonio del Corregidor de Ronda, 1/3/1639. Fe de la vecindad de Ronda y sus arrabales, 24/1/1639. AGS, GA, Leg. 1.261.

75 Carta del Corregidor de Jaén, 22/12/1638. AGS, GA, Leg. 1.266.

76 Junta de Coroneles, 17/1/1639. Relación de la gente remitida hasta el 10/12/1639. Relación de lo que escriben los corregidores, 1639. AGS, GA, Legs. 1.261, 1.273 y 1.277.

77 Relación de los corregidores a quien se han encargado levas, 1/3/1639. Relación de la gente remitida hasta el 10/12/1639. AGS, GA, Legs. 1.278 y 1.273 .

78 Carta del Corregidor de Granada, 15/5/1639. AGS, GA, Leg. 1.261. SALAS ALMELA, L. (2008): Medina Sidonia. El poder de la aristocracia 1580-1670. Madrid, Marcial Pons, pp.361-362. 
de la fuerza, pidiendo algunos que incluso las autoridades judiciales no tomaran cartas en el asunto y propiciaran la liberación de los apresados. Otros, como el corregidor de León, pidió expresamente que se le permitiese actuar contra los estudiantes que "solo lo son en el nombre", al considerarles ociosos. En algunos casos los municipios pagaron voluntarios. Pero lo habitual fue la aplicación de forzados: alistándose a los penados por delitos leves o capturando a vagabundos, transeúntes y ociosos. Con ello se pretendía evitar la realización de cualquier sorteo que propiciara la salida de hombres casados con una ocupación estable. Los enrolados debían ser retenidos en algún lugar, por lo que algunos corregidores -como el de Málaga- evacuaron de la cárcel a todos los galeotes y esclavos que había para meter en su lugar a los soldados. La utilización de la fuerza no fue un verdadero problema, o una de las principales dudas de los corregidores, pero el tema económico fue uno de los más recurrentes. ${ }^{79}$ Cuestión que ya había sido uno de los grandes problemas localizados en el pasado, ya que muchos bienes de propios de las ciudades estaban embargados. Para resolverlo se determinó que para cubrir los gastos se echara mano a distintas rentas reales cobradas en cada partido, por lo que el reclutamiento no sobrecargaba con más costes a los municipios, allanándose la colaboración de los corregidores y las elites locales. Con esta gran novedad se daba más libertad a los ejecutores para agilizar trámites y concluir la leva, cargando la mayoría de los costes sobre diversos impuestos, especialmente las alcabalas, los Millones y el papel sellado. ${ }^{80}$

La programación de la leva, estimada en 8.079 hombres, también era algo diferente. Por un lado, porque no se esperaba llenar todos los presidios, sino que sólo se pretendía enviar tropas a 6 de ellos -los cuales recibirían más fondos para evitar los problemas del pasado-, los antemurales de la defensa contra Francia: Navarra, Guipúzcoa, Cataluña y Aragón; además de Portugal y Cádiz. ${ }^{81}$ Al quedar la gestión en manos de la Junta de Coroneles, muy pronto ésta dejó de lado las pretensiones iniciales y se centró en reclutar al menos 6.000 hombres, los cuales debían remitirse a La Coruña, Cádiz, Cartagena y Málaga, que servirían para reforzar las posiciones

79 Cartas del Corregidor de Granada, 4/1, 15/2 y 8/3/1639. AGS, GA, Leg. 1.261. Relación de lo que escriben los corregidores, 1639. AGS, GA, Leg. 1.277.

80 Carta del conde de Castrillo, Madrid, 15/11/1640. AGS, GA, Leg. 1.273. Relación del gasto que han hecho los corregidores, 1639. AGS, GA, Leg. 1.274.

81 Consejo de Guerra, 16/2/1639. AGS, GA, Leg. 1.255. 
españolas en Italia y Flandes. ${ }^{82}$ Los informes que valoraban el cumplimiento de los cupos son algo confusos. Los realizados internamente por los secretarios del Consejo de Guerra parecen incompletos, ya que no coinciden con los informes de embarques y llegadas remitidos desde los puertos. Los informes internos, indican que se habrían remitido 4.781 soldados, de los que 4.094 llegarían a los puertos y se admitirían; lo que indica que el $14 \%$ de los enviados no llegó a su destino; estando otros 624 preparados para salir. ${ }^{83}$ Dichos informes no coinciden con los remitidos desde Cádiz, en donde hasta mayo habían entrado 2.157 hombres, casi el doble de los que manejaban los informes internos del Consejo de Guerra; ${ }^{84}$ incluso durante los meses siguientes llegaron más hombres. ${ }^{85}$ Algo parecido a lo que ocurrió en La Coruña y Cartagena. ${ }^{86}$ De hecho, una vez finalizado el servicio se demostró que se necesitaba un cómputo y una verificación más precisa, al ser la mayoría de los informes demasiado simples para indagar qué territorios no habían cumplido. Además, era imposible cotejar los datos, que en demasiadas ocasiones no coincidían al estar en manos de diversos secretarios y juntas. ${ }^{87}$

\section{El Reclutamiento: de las ideas de la Corona a las realidades del reino}

En la propuesta inicial quedaba claro que la Corona buscaba voluntarios, por lo que para motivar su alistamiento se determinaron diferentes privilegios a los soldados y premios a los hijosdalgo que se alistaran, garantizándose algunas ventajas a las personas principales que optaran por servir, como un ascenso más rápido dentro del escalafón. También se estipularon

82 Junta de Coroneles, 17/1/1639. AGS, GA, Leg. 1.261. Relación de la gente que está ajustada para Italia, $s / f$. Relación de las personas con quien se ha ajustado levas por la Junta de Coroneles, 24/2/1639. AGS, GA, Leg. 1.258. Relación de las personas que se han ajustado levas y gente que han remitido, $s / f$. Memorias de la gente ajustada para Flandes y para Italia, s/f. AGS,GA, Leg. 1.277.

83 Relación de los corregidores, 1/3/1639. Relación de la gente remitida, 10/12/1639. AGS, GA, Legs. 1.278 y 1.273

84 Relación de la gente que ha entrado, Cádiz, 23/5/1639. AGS, GA, Leg. 1.261.

85 Relaciones de la gente que hubo en Cádiz, Cádiz, 23/7 y 6/8/1639. AGS, GA, Leg. 1.255.

86 Relaciones de la infantería de nuevas levas, La Coruña, 12/2 y 13/3/1639. Relación de la infantería que se ha recibido, Cartagena, desde $11 / 9$ al 3/10/1639. AGS, GA, Leg. 1.273 y 1.279 .

87 Carta del Conde de Castrillo, Madrid, 15/11/1640. AGS, GA, Leg. 1.273. 
Tabla 3: Evolución de las peticiones de levas para los presidios (16341641)

\begin{tabular}{|c|c|c|c|c|}
\hline & Fecha & Número repartido & Motivos & Destinos \\
\hline $1^{\circ}$ Repartimiento & $3 / 3 / 1634$ & 12.000 & & $\begin{array}{l}\text { La Coruña } 284 \\
\text { Guipúzcoa } 1.084 \\
\text { Navarra } 436 \\
\text { Aragón } 638 \\
\text { Cataluña } 3.439 \\
\text { Portugal } 3.305 \\
\text { Cádiz } 1.494 \\
\text { Larache y La } \\
\text { Mámora } 1.320 \\
\end{array}$ \\
\hline $2 \div$ Repartimiento & $4 / 12 / 1635$ & 5.572 & $\begin{array}{l}\text { 2.064 de los que } \\
\text { faltan de } \\
\text { entregar, y } \\
3.508 \text { de los } \\
\text { huidos y muertos } \\
\text { en los presidios }\end{array}$ & $\begin{array}{l}\text { Cádiz } 472 \\
\text { Portugal } 2.644 \\
\text { Guipúzcoa } 542 \\
\text { Cataluña } 1.914\end{array}$ \\
\hline $3^{\circ}$ Repartimiento & $11 / 6 / 1636$ & 2.000 & $\begin{array}{l}2.000 \text { de los que } \\
\text { faltan de los } \\
\text { otros dos } \\
\text { repartimientos }\end{array}$ & $\begin{array}{l}\text { Portugal } 563 \\
\text { Cádiz, Larache y } \\
\text { La Mámora } 1.012 \\
\text { Gibraltar } 303 \\
\text { Melilla } 122 \\
\end{array}$ \\
\hline $4^{0}$ Repartimiento & $10 / 4 / 1637$ & 7.027 & $\begin{array}{l}1.629 \text { de lo que } \\
\text { faltaba del } 3^{\circ} \\
\text { repartimiento, y } \\
5.398 \\
\text { nuevamente }\end{array}$ & $\begin{array}{l}\text { Cataluña } 1.500 \\
\text { Guipúzcoa } 1.000 \\
\text { Galicia } 2.500 \\
\text { Cádiz } 1.500\end{array}$ \\
\hline $\begin{array}{l}\text { 50 Repartimiento } \\
\text { (denominado como } \\
\text { leva de uno por } \\
\text { ciento) }\end{array}$ & $22 / 11 / 1638$ & 8.079 & $\begin{array}{l}\text { Del anterior } \\
\text { faltaron } 1.807\end{array}$ & $\begin{array}{l}\text { Cataluña } 1.500 \\
\text { Cádiz } 2.000 \\
\text { Portugal } 1.500 \\
\text { Guipúzcoa } 2.000 \\
\text { Aragón y } \\
\text { Navarra } 1.073\end{array}$ \\
\hline 6을 Repartimiento & $13 / 2 / 1641$ & 8.049 & & \\
\hline Total: & & 42.727 & & \\
\hline
\end{tabular}

Fuente: AGS, GA, Legs. 1.121, 1.132, 1.144 y 1.147. 
premios, favorables cuidados sanitarios, la posibilidad de pasar a los ejércitos de campaña y diversos privilegios que se concederían al jubilarse tras servir 20 años. A pesar de las condiciones ofrecidas, se tenía claro que no se encontrarían muchos voluntarios, por lo que se regularon las diversas fórmulas mediante las cuales las autoridades "echaran mano de la gente ociosa y malentretenida de la república, sin perdonar a nadie", permitiendo que las ciudades se desembarazaran de ellos. Aun así, se recomendaba a las jurisdicciones que procuraran encontrar el número requerido sin quintar a la población, recurso que sólo se pondría en práctica en última instancia. La colaboración de las audiencias y chancillerías del reino era esencial, ya que se permitía que las autoridades locales se pudieran valer de delincuentes y gente ociosa y de mal ejemplo para cumplir con el cupo, intentándose que éstos se alistaran y que nunca volvieran; persiguiéndose a los infractores. Si como último recurso se efectuaba un sorteo, éste debía incidir especialmente entre los solteros o viudos sin hijos, de 17 a 50 años, para evitar que saliera gente pobre o que dejara a sus hijos desamparados. Incluso, para aliviar el servicio, se reguló un sistema de licencias que permitía que tras cinco años los voluntarios pudieran volver a sus casas, mientras que los sorteados podrían licenciarse tras tres años. ${ }^{88}$

En la práctica las autoridades municipales -ante la imposibilidad de captar voluntarios-, debieron completar los cupos alistando forzosamente a distintos sectores sociales como los vagabundos, ociosos, forasteros y jornaleros que estaban de paso, delincuentes o a cualquiera que trastocara el orden de la comunidad. Así se entiende las escasas tensiones generadas por esta clase de reclutamientos y los pocos disturbios y motines que generaron. ${ }^{89}$ Al dar importantes atribuciones de carácter militar a los mediadores locales de las ciudades, éstos empezaron a actuar como reclutadores directos a cambio de aumentar su poder sobre la población, ${ }^{90}$ poniéndose las bases de futuros reclutamientos forzosos por cupos, que ponían las miras en alistar a todos los delincuentes $\mathrm{u}$ ociosos posibles para evitar los sorteos. ${ }^{91} \mathrm{En}$ 1634 la mayoría de los municipios cumplieron enviando malentretenidos, delincuentes por delitos menores y otros maleantes, ya que al ser ésta la primera vez que se realizaba esta clase de reclutamiento estos sujetos se

88 Forma que las provincias han de guardar en juntar la infantería, s/f. Consejo de Guerra, 20/5/1634. AGS, GA, Leg. 1.095.

89 Sobre posteriores sistemas de reclutamiento obligatorio: RODRÍGUEZ HERNÁNDEZ, Los Tambores de Marte..., pp. 145-196.

90 Sobre la gestión en Murcia: RUIZ IBÁÑEZ, J.J. (1995): Las dos caras de Jano. Monarquía, ciudad e individuo Murcia, 1588-1648. Murcia, Ayuntamiento-Universidad de Murcia, pp. 322-327 y $351-361$. 
podían encontrar con facilidad. La ciudad de Sevilla rápidamente informó que no había encontrado ni un solo voluntario, por lo que recogía a los alistados en las cárceles, temiendo que si no se les enviaba por barco a Cádiz la mayoría se fugaría por el camino. ${ }^{92}$ Durante los años que duró el servicio fue habitual que se buscaran hombres en las cárceles, enviando a todos los condenados posibles, por lo que las galeras perdieron remeros. ${ }^{93}$ Los problemas más graves ocurrieron cuando las justicias y ministros locales aprovechaban la coyuntura para imponerse sobre el común y sacar partido de los nuevos gravámenes. Los informes realizados en Jerez de los Caballeros sacaron a la luz los distintos abusos de las autoridades locales, que en vez de intentar apresar a los vagabundos que nada tenían que ofrecer, se encargaban de molestar y presionar a los hombres honrados con oficio conocido, para que éstos pagaran para librarse. En vez de seguir los cupos, se violentaba a cualquiera que pudiera aportar dinero, que se utilizaba para comprar sustitutos forasteros que se encargasen de servir por los municipios del partido, y llenaba los bolsillos de las autoridades. ${ }^{94}$ Las irregularidades abundaron, y en muchos lugares se procedió a contratar a cualquiera que quisiera servir. ${ }^{95}$

Con el paso de los años la acción de las autoridades locales fue esencial para que el reclutamiento tuviera éxito, pero el problema fue determinar quiénes eran ociosos. En muchos casos se realizaban levas arbitrarias que pretendían capturar a los transeúntes, aunque no fueran vecinos del lugar. En 1637 llegaron a Lisboa nueve soldados del cupo que correspondía a la villa de Porcuna, de los que cuatro pertenecían a la jurisdicción de Trujillo, sujetos que se habían trasladado en busca de trabajo, y que habían sido prendidos sin causa alguna; práctica que fue muy frecuente. ${ }^{96}$ También de manera general se establecieron pautas de servicio, y muchas ciudades intentaron que los soldados fueran siempre voluntarios, ante los problemas que ocasionaba apremiar a distintos sujetos a alistarse. Algunos cabildos

91 Carta del corregidor de Salamanca, 26/2/1636. AGS, GA, Leg. 1.207.

92 Junta de la defensa de estos reinos, 3/6/1634. AGS, GA, Leg. 1.095.

93 Consejo de Guerra, 9/10/1637. AGS, GA, Leg. 1.184.

94 Consejo de Guerra, 21/8/1634. Cartas de algunos clérigos de Jerez, 3/8/1634. AGS, GA, Leg. 1.095.

95 Consejo de Guerra, 30/4 y 28/6/1634. AGS, GA, Leg. 1.095.

96 Carta de la Princesa Margarita, Lisboa, 6/8/1637. AGS, GA, Leg. 1.210. 
como el de Burgos -sensible a la pobreza de la tierra y a su creciente despoblación-, intentaban que sólo se enviasen a servir a los sujetos que menos falta hacían en sus comunidades de origen. ${ }^{97}$ Madrid siempre intentó enviar voluntarios, e incluso acudió a asentistas para que se encargaran de reclutarlos, evitándose problemas a cambio de un importante coste económico. ${ }^{98}$

Durante los últimos repartimientos las órdenes fueron más precisas a la hora de indicar la calidad de los soldados, ante la creciente mala disposición de los enviados. En 1641 se pedía expresamente que los soldados no fueran casados o extranjeros -especialmente portugueses, franceses o catalanes-, al estar en guerra con todos ellos. No siempre conocemos datos precisos de los reclutados, pero esporádicamente algunos archivos municipales han conservado esta documentación. En 1641 la villa de Morón de la Frontera debía contribuir con 32 hombres, aunque sólo pudo remitir 28 a Cádiz en dos tropas a lo largo del verano, de los que 11 no se aceptaron (el 38\%) por diversos motivos. Algunos eran demasiado mayores para servir, otros eran portugueses, tenían enfermedades infecciosas -como la tiña- o estaban lisiados, lo que no les hacía aptos. Incluso uno fue rechazado -al presentar una calentura continua, y fístulas por todo el cuerpo-, ante el miedo de que contagiase al resto. ${ }^{99}$ En enero 1642, ante los incumplimientos de la villa, se volvieron a exigir con urgencia 21 hombres. Las nuevas órdenes intentaban luchar contra el fraude, insistiendo en que se debían entregar sujetos sanos que tuvieran una edad aceptable y sin lesión alguna. Se preferían voluntarios; aunque en caso contrario se debía acudir a los vecinos que fueran ociosos o malentretenidos, evitando capturar a los forasteros que estuvieran de paso en la villa por algún motivo justificado. Si con ello no se podía llenar el número se debía proceder al sorteo a través de las parroquias, admitiéndose sustitutos, especialmente si se trataba de vecinos impedidos o con muchos hijos a los que cuidar y alimentar, los cuales podían pasar esta obligación a alguno de ellos. ${ }^{100}$

La villa cumplió enviando en pocas semanas 12 reclutas, de los que sólo uno fue rechazado por ser un emigrante portugués. La rapidez se debió a

97 Acuerdos del 12/11/1635. AMBurgos, LA de 1635 f. 150v-151v.

98 Papel del marqués de Hinojosa sobre las levas, 1637. AGS, GA, Leg. 1.196.

99 Carta del Veedor Francisco Lorenzo de Losada, Cádiz, 17/7/1641. Carta del Contador Matías Ochoa, Cádiz, 17/3/1642. AMMorón, Leg. 649.

100 Cédula de García Sarmiento de Sotomayor, Asistente de Sevilla, Sevilla, 18/1/1642. Cédula Real, Madrid, 4/1/1641. AMMorón, Leg. 649. 
la aplicación a la recluta de 4 sujetos que salían directamente de la cárcel. Todos ellos eran delincuentes menores -como Juan de Barahona, un quinceañero condenado por "hurtar un cochino"-, a los que se conmutó su pena al alistarse. ${ }^{101}$ Del total de 40 que entregó la ciudad, 13 habían sido condenados. Tres de ellos por deserción, ya que habían huido de las tropas de milicias que se habían sacado por la villa para la frontera. Otros penados lo eran por motivos varios. Alonso Coronil, de 30 años, iba preso -a pesar de estar casado-, al ser condenado por la justicia local por "vagamundo y fama de ladrón". Benito Ximénez, de 34 años, había sido procesado por "amenazas y maltratamiento a su mujer, con peligro de su vida". Juan de Alvarado, de 33 años, por robar una yegua -aunque no había pruebas en su contra-, y por tener causa por vagamundo. Manuel Núñez, de 50 años, había sido condenado por fugitivo de la compañía de milicias de la villa que servía en Ayamonte -y haber vuelto "a la vista de todos"-, y por convivir con una mujer casada, y ser un "hombre inquieto, vagamundo y escandaloso". ${ }^{102}$ A Juan Ríos, de 22 años, se le había apresado por "amancebamiento continuado de mucho tiempo", conmutándosele la pena al alistarse. Gonzalo Gutiérrez, de 40 años, también fue apresado por estar amancebado con una mujer casada, con la que había convivido durante más de 10 años. ${ }^{103}$ El carácter forzado de muchos hacía que las tropas fueran enviadas fuertemente custodiadas por hombres armados. El primer grupo de 18 soldados que salió de Morón fue acompañado por un comisario montado, tres alguaciles a caballo y otros dos guardas a pie: un escolta por cada tres soldados. Además, los hombres llevaban 11 pares de esposas, para utilizarlas de dos en dos; gastándose un total de 651 reales. ${ }^{104}$

101 Listado de la tropa, Morón de la Frontera, 22/1/1642. Carta del veedor Juan López, Cádiz, 25/2/1642. AMMorón, Leg. 649.

102 Cédula de García Sarmiento de Sotomayor, Asistente de Sevilla, Sevilla, 10/4/1641. Cédula Real, Madrid, 13/2/1641. Listado de los soldados, Morón de la Frontera, julio 1641. AMMorón, Leg. 649.

103 Listado de los soldados, Morón de la Frontera, 3/8/1641. AMMorón, Leg. 649.

104 Tasación y Auto de los costes, julio 1641. Carta del Veedor Francisco Lorenzo de Losada, Cádiz, 17/7/1641. Carta del contador Matías Ochoa, Cádiz, 17/3/1642. AMMorón, Leg. 649. 
La mayoría de los reclutados decían ser originarios de la villa o los alrededores según las filiaciones que reconocían en los listados; a pesar de lo cual varios fueron rechazados por los oficiales reales de Cádiz por ser portugueses. Respecto a la edad media de los reclutas había mucha más variedad. Más del $60 \%$ eran sujetos de menos de 30 años, aunque también se mandaron en las compañías a 3 sujetos de 50 años o más; sin duda personas demasiado mayores para la milicia, que fueron rechazadas por los veedores de Cádiz. La baja edad media de los reclutas nos indica que muchos habían sido elegidos por no tener oficios ni familia.

Edades de los hombres aportados por Morón de la Frontera (1641-42)

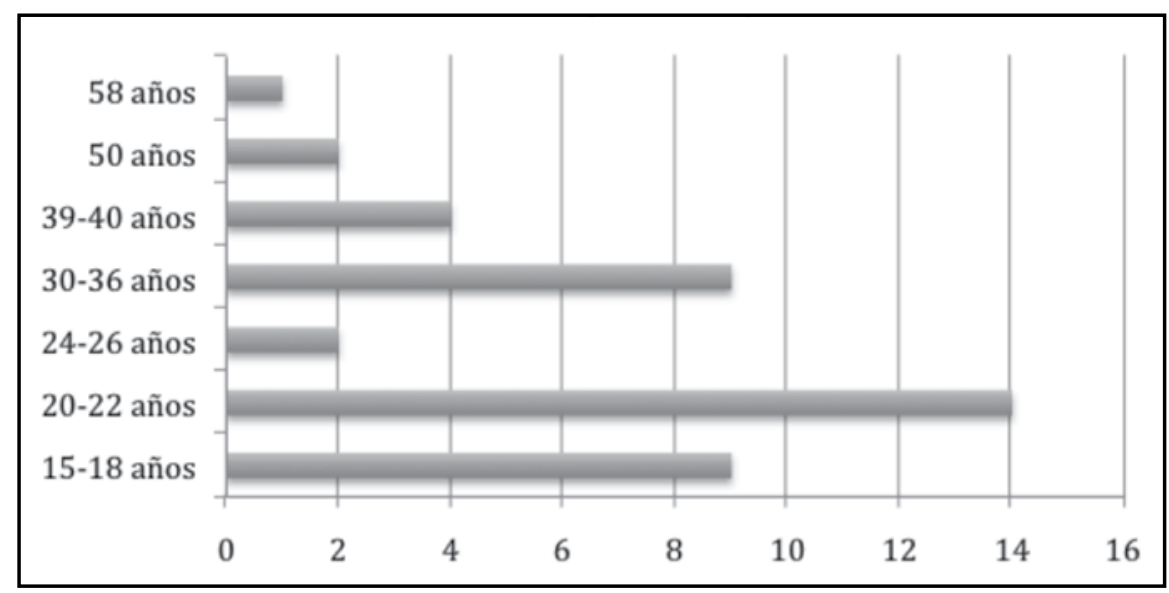

Fuente: AMMorón, Leg. 649.

\section{4. ¿Reclutar los presidios O los ejércitos de la monarquía?}

Los presidios hispanos de Portugal se beneficiaron especialmente de la llegada de nuevos reclutas, ya que desde hacía tiempo faltaban hombres. En febrero de 1634 en los castillos del reino había sólo 695 hombres. ${ }^{105}$ Un año después eran ya 1.335, incluidos los enfermos, gracias a que durante los meses anteriores habían llegado 1.163 bisoños. La calidad de éstos dejaba bastante que desear para los mandos militares, que no confiaban demasiado en su capacidad militar, ya que se necesitaban veteranos para defender adecuadamente el reino y participar en las expediciones marítimas a Brasil. Además, su número se reducía con rapidez debido a las fugas, y especialmente a la mortandad. Entre agosto de 1634 y febrero del 
año siguiente habían muerto en el hospital 55. ${ }^{106} \mathrm{El}$ notable incremento de la dotación permitió que se enviaran refuerzos a los presidios dependientes que mantenían una guarnición española. A finales de año se remitieron 100 hombres a la isla de Madeira y otros 90 a las Azores; algo que hacía tiempo que no era posible. ${ }^{107}$

Gracias a la documentación relativa a la dotación real -mes por mes- presente en Portugal durante 1637, y los informes de llegadas de los reclutas, podemos obtener una imagen bastante precisa de la importancia de la llegada de estos refuerzos, y el papel de los presidios como correas de distribución del poder militar de la monarquía. Según los datos de llegadas, entraron en los presidios 1.171 soldados, aunque faltarían varias partidas por computarse, como la relativa a octubre. ${ }^{108}$ La dotación real del presidio fue variando progresivamente por diferentes factores, siendo básico para comprender su descenso la amplia participación de las tropas en otros frentes. Según las órdenes, entre finales de 1635 y finales de 1637 debían haber llegado teóricamente 3.948 nuevos soldados. ${ }^{109}$ Pero muchos de los recién llegados se remitieron a otros frentes o se embarcaron en la Armada. En octubre de 1636 el duque de Nájera sacó 1.340 infantes de Lisboa para tripular 10 navíos -la mayoría mercantes embargados que carecían de infantería-, que se movilizaban para engrosar la Armada que debía combatir a los franceses. ${ }^{110}$ A comienzos de 1637 se envió un refuerzo de

106 Carta de la Princesa Margarita, Gobernadora de Portugal, Lisboa, 14/2/1635. Carta de Fernando de Toledo, Lisboa, 17/2/1635. Relación de las tropas de infantería, Lisboa, 17/2/1635. Relación de los oficiales y soldados del Tercio, Lisboa, 17/2/1635. Relación de los soldados que han muerto en el hospital, s/f. AGS, GA, Leg. 1.145.

107 Carta de la Princesa Margarita, Gobernadora de Portugal, Lisboa, 3/9/1635. AGS, GA, Leg. 1.140.

108 Varias relaciones de los oficiales y soldados que están de guarnición en Portugal, enero a agosto de 1637. Dos relaciones de las tropas que han entrado en el reino, Lisboa, 11/7 y 20/9/1637. AGS, GA, Leg. 1.195. Relaciones de los oficiales y soldados del tercio, septiembre y noviembre de 1637. Relación de las tropas que han entrado en el castillo, Lisboa, 28/11/1637. AGS, GA, Leg. 1.205.

109 Relación de lo que toca a cada presidio, s/f. Notas del segundo y tercer repartimiento, $s / f$. AGS, GA, Leg. 1.194.

110 Junta de Armadas, 25/4 y 25/7/1636. AGS, GA, Leg. 3.167. Memoria que se ha sacado para enviar a Fernando de Contreras, s/f. AGS, GA, Leg. 1.194. Carta de la princesa Margarita, Gobernadora de Portugal, Lisboa, 8/10/1637. Relación de la gente de mar y guerra embarcada, Lisboa, 7/10/1637. AGS, GA, Leg. 1.201. 
100 hombres a las Azores. ${ }^{111}$ Pero a lo largo de ese año fundamentalmente los hombres de los presidios fueron reclamados para reforzar las Armadas que se pertrechaban en Lisboa. De hecho, más de una veintena se fugaron al embarcar, llegando a fugarse un cabo de escuadra que estaba de guardia. ${ }^{112}$ Los continuos envíos a otros frentes, y las fugas, justifican que la dotación del presidio no aumentase significativamente -como podemos observar en la gráfica-, lejos de cubrir los 3.640 hombres asignados.

No es fácil valorar en conjunto la contribución real de los distintos repartimientos del reino sobre la evolución general de la guarnición de los presidios, pero sí queda claro que después del primer reparto los siguien-

\section{Presidios de Portugal (1637): relación entre la llegada de nuevos re- clutas y su dotación}

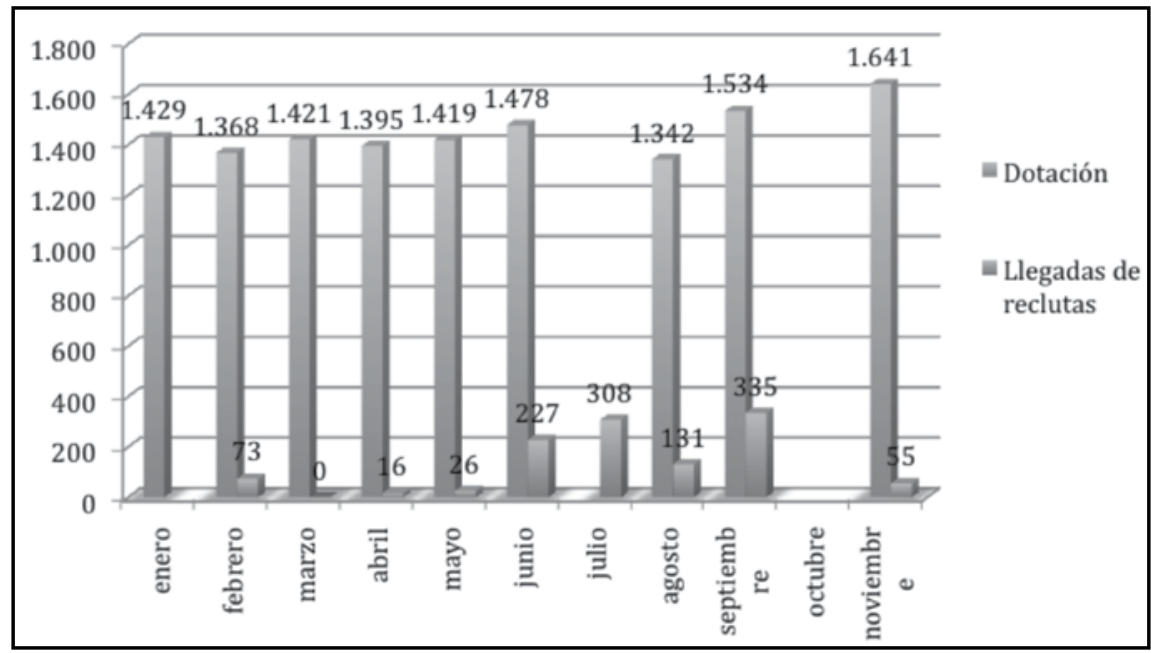

Fuente: AGS, GA, Legs. 1.194, 1.195 y 1.205.

111 Relación de la gente que hay en los presidios, Madrid, 24/3/1637. AGS, GA, Leg. 1.094.

112 Junta de Armadas, 9/2/1636. AGS, GA, Leg. 3.167. Carta de Fernando de Alvia de Castro, Lisboa, 17/1/1637. AGS, GA, Leg. 1.201. Cartas de la princesa Margarita, Gobernadora de Portugal, Lisboa, 11/5, 7 y 14/6/1637. Carta de Tomás de Ibio Calderón, Lisboa, 7/6/1637. AGS, GA, Leg. 1.206. Cartas de Tomás de Ibio Calderón, Lisboa, 3 y 5/7/1637. AGS, GA, Leg. 1.207. 
tes no valoraron o cuantificaron la necesidad real de los presidios. Eso contradecía las bases del servicio realizado por el reino, ya que una vez llegaron los nuevos reclutas a los presidios se debía cuidar el fraude y las plazas supuestas para evitar nuevas levas. Se pretendía que cada dos meses se pasara muestra para saber así los soldados que faltaban y atender a la persecución de los fugitivos, pudiendo contabilizarse cuantos soldados eran necesarios como reemplazo. ${ }^{113}$ Todo ello quedó bajo la vigilancia de la Junta de Presidios, ${ }^{114}$ que periódicamente insistía en tener relaciones pormenorizadas de la gente que faltaba. ${ }^{115}$ Pero en los sucesivos repartos la cuantía de hombres no se fijó en relación a las bajas surgidas. Es cierto, como podemos ver en la tabla adjunta, que los presidios mejoraron sus dotaciones gracias al servicio aprobado por las Cortes, pero su incremento no fue tan notable ante la continua práctica de enviar a parte de las tropas a otros frentes y las numerosas fugas. De hecho, a lo largo de un año podían entrar casi tantos nuevos reclutas como soldados morían, se fugaban o eran licenciados. Entre marzo de 1636 y el mismo mes del año siguiente entraron en Fuenterrabía y San Sebastián 266 nuevos reclutas, frente a los 220 que se dieron de baja, mayoritariamente por fuga. A pesar de los grandes esfuerzos del reino difícilmente los presidios permanecían llenos. ${ }^{116}$

En Cádiz el impacto de la continua llegada de soldados parece que fue menor que en otros presidios, debido a lo poco que las nuevas tropas contribuyeron a reforzar la dotación. Es cierto que en los primeros años las excesivas fugas no ayudaron, pero éstas tendieron a controlarse, a pesar de que las condiciones de vida no cambiaron significativamente. En 1637 algunos oficiales se quejaban de que los nuevos reclutas debían estar encerrados en los castillos, y que en ellos no se les procuraba el alojamiento adecuado, siendo escaso el socorro que se les suministraba. Durante el invierno debieron dormir en el suelo, estando desnudos y descalzos, sin que se pudiera atender su falta de abrigo. Eso producía que muchos quisieran huir y que se tiraran por la muralla para intentar escapar, lo que había producido algunos accidentes y muertes. Aun así las deserciones no estaban

113 Forma que las provincias han de guardar en juntar la infantería. AGS, GA, Leg. 1.095.

114 Sobre esta Junta: BALTAR RODRÍGUEZ, J.F. (1998): Las Juntas de gobierno de la Monarquía Hispánica (S. XVI-XVII). Madrid, Centro de estudios políticos, pp. 377 y ss.

115 Junta de Presidios, 12/12/1634. AGS, GA, Leg. 1.096.

116 Relaciones de las tropas que han entrado en San Sebastián y Fuenterrabía, 9/4 y 1/5/1637. AGS, GA, Legs. 1.195 y 1.197. 
Tabla 4: Dotación teórica y real de los Presidios (1634-1640)

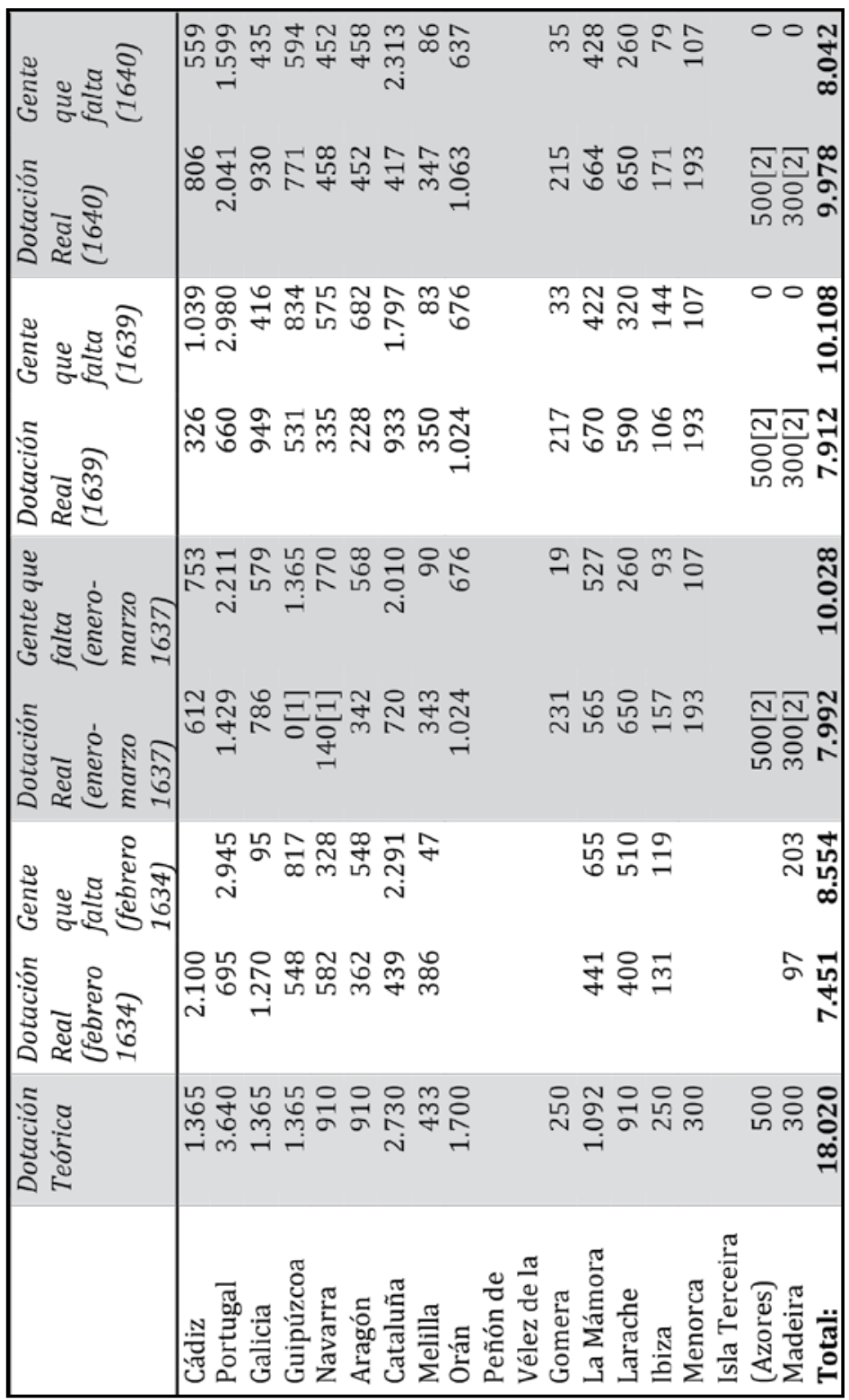

Fuente: AGS, GA, Legs. 1.038, 1.194, 1.095, 1.277 y 1.387. Notas: [1]: Están movilizados con el ejército en la frontera. Según la muestra de junio de 1637, en el ejército de Fuenterrabía había 11 compañías sacadas de distintos presidios: 307 hombres de los presidios de Navarra y Aragón, 495 de los presidios de Guipúzcoa y 272 de los presidios de Galicia: 1.074 en total (Relación de los oficiales y soldados..., Fuenterrabía, 26/6/1637. AGS, GA, Leg. 1.202). [2]: Cifras supuestas. 
siendo tan significativas. En enero de 1637 habían llegado 830 hombres de las levas del reino, de los cuales 300 habían pasado a reforzar Larache y La Mámora, 370 se agregaron a las compañías del presidio y 160 habían huido. ${ }^{117}$ Entre abril y octubre de ese mismo año pudieron entrar en el presidio 506 nuevos reclutas de diferentes levas, de los que sólo uno fue despedido, otro murió y 10 se fugaron; lo que dejaba un balance bastante positivo. Pero en general la dotación media del presidio fluctuó durante todo el año, y dependió demasiado de la llegada de nuevos refuerzos y lo poco que persistían los nuevos reclutas. ${ }^{118}$ En 1639, de los 2.157 hombres remitidos a Cádiz, muy pocos se fugaron, fueron despedidos o murieron: 130 en total. Pero lo más preocupante es que sólo 11 de ellos se habían agregado a las compañías fijas del presidio, y aunque otros 115 estaban todavía en Cádiz -tanto en el hospital como fuera-, éstos estaban a la espera de ser enviados a otros lugares. De hecho 963 se habían remitido a Flandes, 495 a las Indias, 179 habían reforzado la Armada y 264 se habían enviado a los presidios norteafricanos; lo que significaba que 3 de cada 4 se enviaban a servir fuera de la península o la Armada, y que muy pocos realmente estaban reforzando los presidios peninsulares o africanos. ${ }^{119}$ Datos que dejan en evidencia que, especialmente desde 1639, la leva de los presidios se convirtió en un sistema de reclutamiento encubierto para otros destinos.

Ciertamente la permanencia de los soldados no siempre era la deseada, lo que unido a la continua necesidad de la monarquía de reforzar sus posiciones en Europa contribuyó a que buena parte de los reclutados se enviaran fuera de España. Muchos terminaron engrosando los ejércitos de campaña que se formaron en las fronteras peninsulares. Cuando se completaba el cupo de algunos presidios -e incluso sin que éstos estuvieran completos-, los soldados que sobraban en vez de repartirse por el resto de presidios a los que faltaba dotación se solían embarcar en la Armada o se enviaban a los ejércitos de Italia o Flandes. Esa práctica se convirtió en habitual. A finales de 1635 llegaron a Málaga 366 hombres de la leva para Melilla

117 Cartas de Juan de Velasco y de Leonardo Camargo, Cádiz, 18/1 y 1/2/1637. Carta del duque de Medina Sidonia, Sanlúcar de Barrameda, 18/1/1637. AGS, GA, Leg. 1.209.

118 Seis relaciones de los soldados bisoños que han entrado en Cádiz entre abril y mayo, junio, julio, agosto, septiembre y octubre. AGS, GA, Leg. 1.205.

119 Relación de la gente que ha entrado en este presidio de Cádiz, 23/5/1639. AGS, GA, Leg. 1.261 . 
y el Peñón Vélez de la Gomera. Tras enviar a esas dotaciones 150, se dio orden para que los otros 254 que quedaban se enviaran a Italia. ${ }^{120}$

La práctica de tomar prestados hombres de los presidios para otros destinos fue demasiado común y muy confusa. En el verano de 1635 el duque de Cardona avisaba de que esperaba con urgencia 400 hombres de los presidios de Aragón que se le habían prometido para reforzar Cataluña, si bien al mismo tiempo se habían ofrecido al marqués de Villafranca otros 500 de los mismos presidios para reforzar sus galeras. En esos momentos había 350 en la raya de Aragón, pero no se sabía para quién eran. ${ }^{121}$ En otros casos se daba orden de embarcar a parte de los hombres de los presidios en las flotas, a pesar de que no había suficientes. ${ }^{122}$ En 1635 se dio orden para enviar a Flandes a 800 hombres del presidio de Pamplona, tarea imposible ya que no había tantos. ${ }^{123}$ En muchos casos se enviaban tropas de los presidios a los ejércitos de campaña peninsulares o a las fronteras más amenazadas como una medida temporal para intentar reforzar la zona con tropas medianamente preparadas. A comienzos de 1637 se mandaron a la frontera guipuzcoana 400 infantes de los presidios gallegos, los cuales colaboraron activamente en el sitio de Fuenterrabía y las operaciones militares de la región. Tres años después se permitió que estas compañías se reincorporaran a sus destinos, aunque para entonces ya sólo disponían de un puñado de oficiales ante el desgaste padecido. ${ }^{124}$ De hecho, la mayoría de los enviados en 1637 eran nuevos reclutas aportados por el reino de Galicia, que reunió 461 hombres a cargo de los tres primeros repartimientos. En 1637 el $85 \%$ del total seguía en sirviendo al rey: 328 en la Armada, Flandes o la frontera con Francia, y sólo 65 estaban de guarnición en La Coruña, su verdadero destino. ${ }^{125}$

120 Consejo de Guerra, 13/9 y 8/11/1635. AGS, GA, Leg. 1.124. Relación de la infantería embarcada, Barcelona, 27/11/1635. AGS, GA, Leg. 1.125.

121 Carta del duque de Cardona, Perpiñán, 12/7/1635. AGS, GA, Leg. 1.147.

122 Junta de Armadas, 7/7/1636. AGS, GA, Leg. 3.167.

123 Carta del marqués de Valparaíso, Pamplona, 20/4/1635. AGS, GA, Leg. 1.146.

124 Consejo de Guerra, 28/2/1637 y 15/1/1639. Carta del duque de Nochera, Fuenterrabía, 10/3/1637. AGS, GA, Legs. 1.185, 1.255 y 1.200 .

125 Tres relaciones de la infantería que ha entrado en la ciudad a cargo de los repartimientos, La Coruña, 19/4/1637. AGS, GA, Leg. 1.205. 


\section{El final del SeRVicio}

Las Cortes de Castilla prorrogaron el servicio en agosto de 1640, hasta que terminase el servicio económico de los veinticuatro millones asociado, que expiraba en $1644 i^{126}$ asegurándose al reino posteriormente que no se volverían a sacar soldados forzados. ${ }^{127}$ Pero el verdadero elemento decisivo para su final fue que el último repartimiento coincidió con una coyuntura muy diferente, al haber estallado las rebeliones de catalanes y portugueses, colisionando el sistema con los apercibimientos y la salida general de las milicias en las zonas fronterizas, lo que hacía imposible que el reparto se desarrollara de manera adecuada, especialmente en la frontera con Portugal. ${ }^{128}$

Ya antes el sistema estaba herido de muerte, ante los incumplimientos de cupos, ${ }^{129}$ y la extensión de todo tipo de reclutamientos por la geografía castellana. Las levas para los presidios no fueron las únicas que se produjeron en Castilla, ya que las condiciones negociadas en las Cortes no se respetaron, y en la práctica las levas no cesaron, sino más bien se multiplicaron, ante la creciente demanda de soldados. Con el tiempo se vieron los resultados de tan importante actividad, y sus consecuencias demográficas. Según un informe de la ciudad de Sevilla, desde abril de 1634 -cuando se instauró el primer repartimiento- hasta 1641, habían salido de su partido 6.300 hombres, siendo la mayoría prendidos por vagabundos o delincuentes. ${ }^{130}$ Muy pronto las levas hicieron mella, y diferentes autoridades regionales avisaron que año tras año había menos mozos a los que recurrir, ${ }^{131}$ incluso algunos se casaban tras haber sido reunidos en la cárcel para intentar eximirse. ${ }^{132}$

126 MACKAY, Los límites..., p. 71

127 Cédula para que se guarde al reino condición sobre que no se saquen soldados involuntarios para la presidios, Toro, 29/7/1650. BN, ms.934 f. 156

128 Junta de Ejecución, 11/3/1641. AGS, GA, Leg. 1.374.

129 Relación de las provincias a quienes les faltan de entregar soldados de los tres repartimientos que se han hecho, s/f. AGS, GA, Leg. 1.259.

130 Carta de García Sarmiento de Sotomayor, Maestre de Campo General de Sevilla, Sevilla, 13/1/1641. AGS, GA, Leg. 1.383.

131 Carta de Juan de Salazar y Velasco, Burgos, 8/4/1637. AGS, GA, Leg. 1.185.

132 Carta del corregidor de Salamanca, 28/4/1637. AGS, GA, Leg. 1.207. Cédula de García Sarmiento de Sotomayor, Asistente de Sevilla, Sevilla, 10/4/1641. Cédula Real, Madrid, 13/2/1641. AMMorón, Leg. 649. 
La proliferación de levas y servicios fue muy importante. Entre 1640 y 1641 la ciudad de Burgos recibió dos llamamientos para cumplir con nuevos cupos de la leva de los presidios y acudir a los pasados, al mismo tiempo que atendía continuos y nuevos requerimientos militares que la ciudad a duras penas podía soportar ante su "acabamiento y falta de vecinos". En enero de 1640 recibía la orden de reclutar 10 hombres para el Regimiento de Guardia del Conde Duque, al mismo tiempo que la provincia reunía 120 mulas para el ejército y seguía pagando los gastos ocasionados por el alojamiento de soldados napolitanos. En abril se daba orden para que los hijosdalgo salieran formando una compañía de caballos; y en octubre las milicias eran convocadas a acudir a Molina de Aragón. Pero durante ese año el cabildo recibió tres condutas de capitanes que reclutaban voluntarios en la ciudad y otros lugares. Todo ello a pesar de que el primer capitán tuvo tan poco éxito que se debió marchar a otros distritos en busca de reclutas. En 1641 el panorama fue parecido, y a los requerimientos de los presidios se sumó la salida de las milicias en agosto; presentándose en la ciudad cuatro capitanes que pretendían reclutar sus compañías. ${ }^{133}$

Otro gran problema -que se sumaba a que muchos municipios no cumplían los cupos-, estaba en la alta tasa de hombres rechazados; la cual parece que pudo crecer con el tiempo ante la falta de voluntarios útiles. Eso suponía un gasto en balde para los municipios, que debían reponer los hombres no entregados. Entre 1634 y 1635 sabemos que el número de hombres no recibidos en Cádiz, de 2.033 casos contabilizados, ascendió al 8,3\%. ${ }^{134}$ En 1639 entre los 141 remitidos a Barcelona por Cuenca y Soria, otro $8,6 \%$ no fue admitido; siendo bastante reveladores los motivos: ser demasiado jóvenes (4), tener mal el corazón (3), padecer "mal de asma" (1), por loco (1), por estar muy sordo (1), estar tullido de un pie (1), o ser extranjero (1). ${ }^{135}$

A todo ello había que sumar el clamor popular que pretendía que estos reclutamientos finalizasen, ante lo poco efectivos que eran y lo mal vistos que empezaban a estar. Los propios veedores y oficiales reales les permitían la vuelta a sus casas a cambio de dinero, y éstos desertores formaban pequeñas cuadrillas que se dedicaban a habitar despoblados, robar para subsistir, e incluso algunos habían ocupado algunas dependencias de la

133 AMBurgos, LA de 1640 f. 21, 38, 51, 53, 55, 66, 140, 157 y 178; y 1641 f. 50, 68, 75 , $82,86,127,163$ y 179

134 Relación de la gente que ha llegado, Cádiz, 31/7/1635. AGS, GA, Leg. 1.147.

135 Relación de la gente que han remitido Soria y Cuenca, Barcelona, 30/4/1640. AGS, GA, Leg. 1.272. 
Alhambra de Granada al no habérselo podido impedir el corregidor. ${ }^{136} \mathrm{~A}$ comienzos de ese año el obispo de Cádiz escribía a Madrid diciendo que en el Castillo de Santa Catalina había 156 mozuelos -de 15 a 16 añosencerrados desde hacía año y medio. Muchachos "arrebañados" de las ciudades de la comarca a título de soldados de leva. Sujetos que por su edad sólo podían servir como mochileros, y que dormían en el suelo sin ningún tipo de abrigo, recibiendo para mantenerse sólo pan y agua. Todos estaban "en carnes", y algunos padecían sarna y otras enfermedades, por lo que muchos estaban en el hospital. El obispo pedía que se les sacase de alli, "aunque sea para el infierno", porque la población comenzaba a aborrecer la milicia. La Junta de Ejecución ordenó su liberación ante la mala prensa que suponía mantenerlos encerrados, queja que empezaba a colmar el vaso. ${ }^{137}$

\section{Conclusiones}

Gran parte de los acuerdos tomados en Cortes de Castilla fueron incumplidos. La recluta de los presidios no acabó con el reclutamiento -y su problemática-, y tampoco acabó con la necesidad de reclutas. Es cierto que la monarquía dejó de enviar capitanes comisionados a las ciudades para que reclutarán directamente en su nombre, pero estos fueron sustituidos por multitud de agentes de la nobleza que se comprometió a formar sus coronelías, y de distintos particulares y asentistas que a cambio de dinero y honores se hicieron cargo del reclutamiento. Intermediarios que provocaron un mayor número de quejas. ${ }^{138}$ Incluso, como se demostró, el reclutamiento aprobado por Castilla no estaba sirviendo para su propia defensa -o la defensa del Norte de África, o los reinos de Navarra, Aragón o Cataluña-, sino especialmente para suministrar reclutas de dudosa calidad a los ejércitos españoles de Italia y Flandes. El esfuerzo militar realizado fundamentalmente por Castilla fue loable, y contribuyó a mejorar las defensas peninsulares -especialmente las de Cataluña-; pero con el tiempo sería un esfuerzo en vano al no destinarse los suficientes recursos para mantener a largo plazo a los hombres que se enviaban.

La leva sería muy importante al marcar un antes y un después dentro de los sistemas de reclutamiento, y allanar el camino a otros métodos coerci-

136 Carta del Corregidor de Granada, 15/5/1639. AGS, GA, Leg. 1.261.

137 Carta del obispo de Cádiz, 3/2/1641. Junta de Ejecución, 19/2/1641. AGS, GA, Leg. 1.374 .

138 Consejo de Guerra, 23/11/1635. AGS, GA, Leg. 1.124. 
tivos que aparecerían posteriormente. Sería la primera recluta obligatoria elaborada en base a cupos distribuidos territorialmente, algo que imitarán otras muchas reclutas en Castilla durante la segunda mitad del siglo XVII. También tendría el dudoso honor de ser la primera leva que intente centrar su atención en alistar de manera general vagabundos, ociosos y penados por delitos leves para intentar así no realizar sorteos o quintar a la población; política que generará pocas resistencias sociales, pero que tendrá como resultado soldados de ínfima calidad muy proclives a la deserción. En contraposición a lo que ocurría con el sistema voluntario tradicional, que no aseguraba resultados, pero sí calidad; esta clase de levas eran efectivas y cubrían cupos humanos importantes que no se podían alcanzar reuniendo voluntarios. Además, la gestión realizada demostrará la enorme potencialidad que tenían los corregidores y presidentes de chancillerías a la hora de abordar reclutamientos, algo que será aprovechado rápidamente. ${ }^{139}$ También el sistema demostró que lo más eficaz para sufragar los gastos era utilizar los impuestos reales que se cobraban in situ, algo que generaba ahorro y evitaba problemas; especialmente si los costes debían ser remitidos directamente por los pagadores del Consejo de Guerra, o recaían en las mismas autoridades municipales. 